San Jose State University

SJSU ScholarWorks

Master's Theses

Master's Theses and Graduate Research

Summer 2021

\title{
How Do You Handle That? How Graduate Teaching Associates Engage in Sensemaking Practices to Overcome Challenges
}

Laura Bell

San Jose State University

Follow this and additional works at: https://scholarworks.sjsu.edu/etd_theses

\section{Recommended Citation}

Bell, Laura, "How Do You Handle That? How Graduate Teaching Associates Engage in Sensemaking Practices to Overcome Challenges" (2021). Master's Theses. 5195.

DOI: https://doi.org/10.31979/etd.rgqk-y4jg

https://scholarworks.sjsu.edu/etd_theses/5195

This Thesis is brought to you for free and open access by the Master's Theses and Graduate Research at SJSU ScholarWorks. It has been accepted for inclusion in Master's Theses by an authorized administrator of SJSU ScholarWorks. For more information, please contact scholarworks@sjsu.edu. 
HOW DO YOU HANDLE THAT? HOW GRADUATE TEACHING ASSOCIATES ENGAGE IN SENSEMAKING PRACTICES TO OVERCOME CHALLENGES

A Thesis

Presented to

The Faculty of the Department of Communication Studies

San José State University

In Partial Fulfillment

of the Requirements for the Degree

Master of Arts

by

Laura E. Bell

August 2021 
(C) 2021

Laura E. Bell

ALL RIGHTS RESERVED 
The Designated Thesis Committee Approves the Thesis Titled

HOW DO YOU HANDLE THAT? HOW GRADUATE TEACHING ASSOCIATES ENGAGE IN SENSEMAKING PRACTICES TO OVERCOME CHALLENGES

by

Laura E. Bell

APPROVED FOR THE DEPARTMENT OF COMMUNICATION

SAN JOSÉ STATE UNIVERSITY

August 2021

Tabitha Hart, Ph.D.

Department of Communication Studies

Shawn Spano, Ph.D.

Department of Communication Studies

Deanna L. Fassett, Ph.D.

Assistant Vice Provost for Faculty

Development, SJSU 


\title{
ABSTRACT \\ HOW DO YOU HANDLE THAT? HOW GRADUATE TEACHING ASSOCIATES ENGAGE IN SENSEMAKING PRACTICES TO OVERCOME CHALLENGES
}

\author{
by Laura E. Bell
}

The aim of this study is to explore the experiences of Graduate Teaching Associates (GTAs) and how they communicate about the challenges they face. Initially, I examined how GTAs describe difficult experiences they have during and outside of the classes that they teach or help facilitate. Then, I investigated how GTAs describe the way they recover readily from these challenging situations and continue to learn from them through the process of sensemaking. Drawing on data from in-depth interviews with 13 GTAs from six different departments at San Jose State University, a thematic analysis was conducted to connect the information shared by all of the participants. Using Weick's sensemaking theory as a framework, I analyzed the themes present within the interview responses to further illuminate the communication about GTA experiences within this specific university. The research identifies ways in which GTAs talk about their challenges: using open communication to talk with others, engaging in sensemaking, and reflectively thinking about their actions. Further, it highlights examples of actions GTAs take, such as leaning on their community, talking to their students and professors, and taking care of their mental health. This research provides updated data in communication studies on the experiences of GTAs while simultaneously illustrating the sensemaking practices that they use to help them overcome challenges. After discussing the implications of this research for practitioners, the study offers suggestions for how the data could help bridge gaps in subfields of communication. 


\section{ACKNOWLEDGMENTS}

To my advisor, Dr. Tabitha Hart: I will never have enough words to adequately thank you for all you have done for me. Your support and consistent encouragement caused me to want to write this thesis in the first place, and it helped sustain me on the days when I did not know if I could write another word. Your teaching has grounded me, and your mentorship has provided me with tools I will use for the rest of my career and beyond. Thank you for modeling what it means to have a strong mind and a kind heart. Because of you, I will seek to never become stagnant in my own growth, and I will not be afraid to make a mess.

To my committee members, Dr. Deanna Fassett and Dr. Shawn Spano: Our conversations surrounding this document caused me to think more critically about this research than I ever had before. Thank you for pushing me, reassuring me, and asking questions that guided me in my own sensemaking to make this thesis the best it could be.

To my fellow GTAs: Thank you all for letting me into your world and for sharing your lives with me. Your voices and perspectives deserve to be heard, and listening to you has made me a better teacher, student, and friend. You are resilient.

To my friend Elaine: I have an infinite amount of gratitude for your wisdom, proofreading, and constant support. Together, we did it! I owe so much to you.

To my parents: Your love has empowered me to keep going and not give up, even in the midst of challenges. Thank you for giving me everything you possibly could.

To Roy: Without you, this paper simply would not exist. I love you more.

Finally, to God: This work is an offering of worship unto you. All glory is yours. 


\section{TABLE OF CONTENTS}

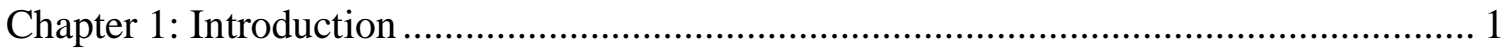

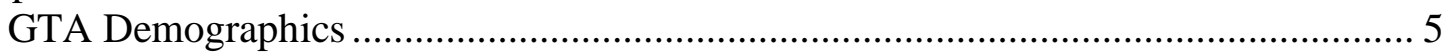

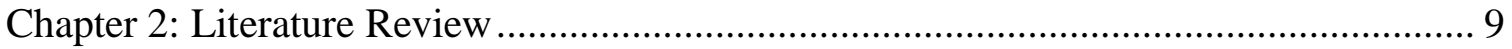

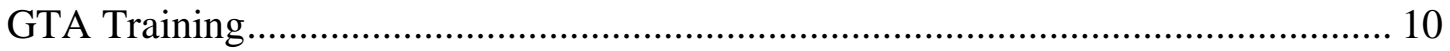

GTA Training in Communication Studies ........................................................ 10

GTA Training Across Disciplines …………................................................. 11

Challenges in the Academy ............................................................................ 14

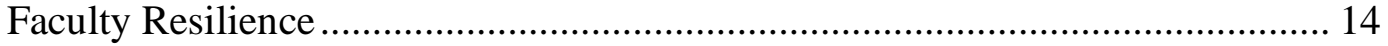

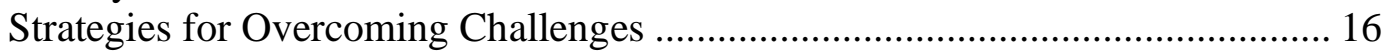

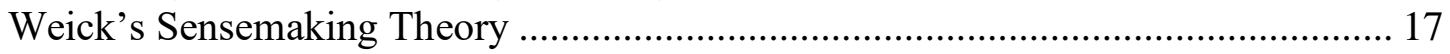

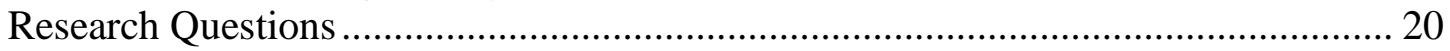

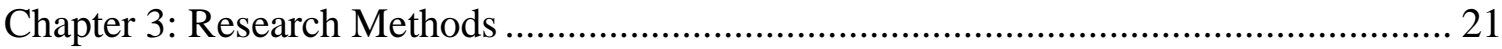

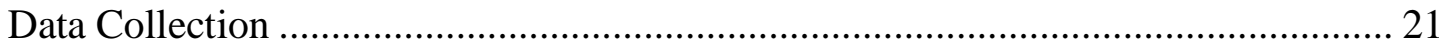

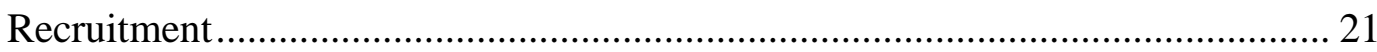

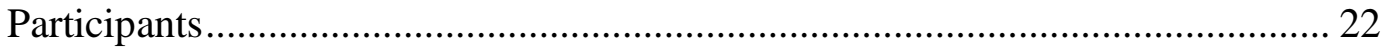

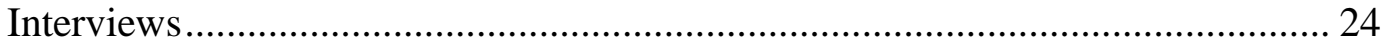

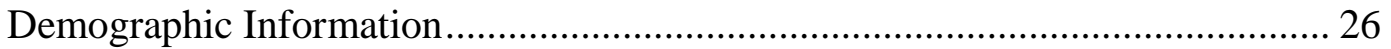

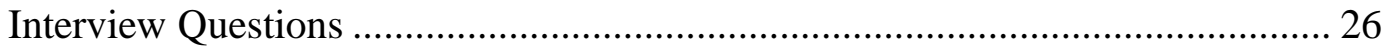

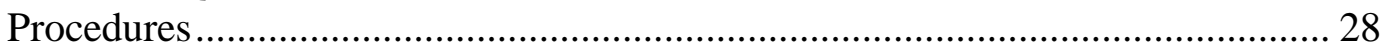

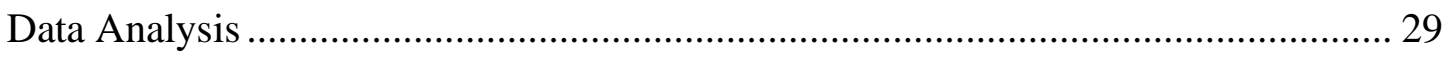

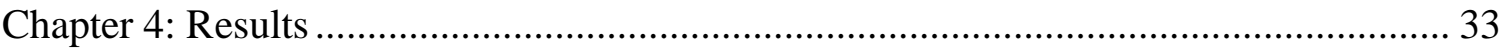

RQ1: How do GTAs communicate about the challenges that they experience?........ 34

GTAs Engage in Honest and Open Communication ........................................... 36

GTAs Describe Their Feelings ……….......................................................... 39

GTAs Pose Reflective Questions to Themselves............................................... 42

GTAs Discuss Challenges with Other GTAs................................................. 44

GTAs Explain Challenges to Their Students ....................................................... 46

GTAs Process Through Situations with Outsiders ………................................... 47

RQ2: How do GTAs at SJSU make sense of these challenges? .................................. 49

Sensemaking through Enactment................................................................... 51

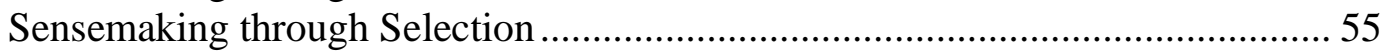

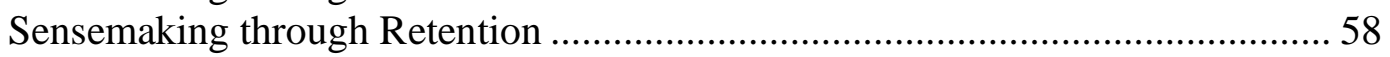

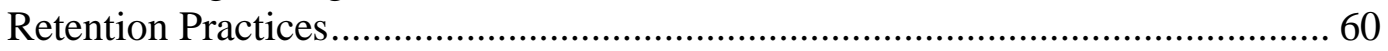

RQ3: What actions do GTAs take to overcome these challenges?............................... 64

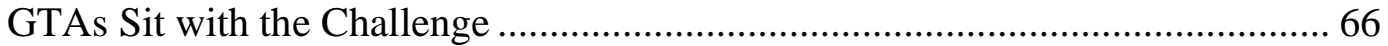

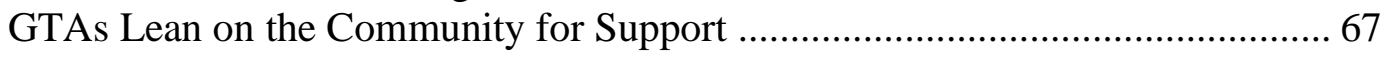

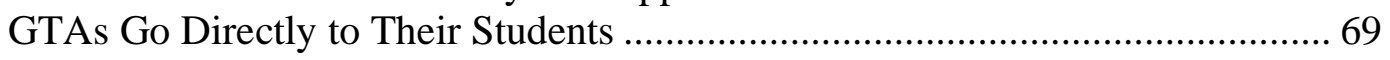

GTAs Utilize Professors and Mimic Their Responses ........................................ 72 


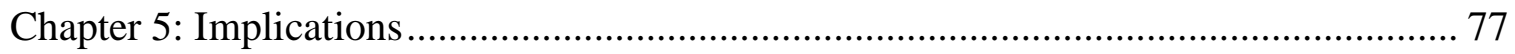

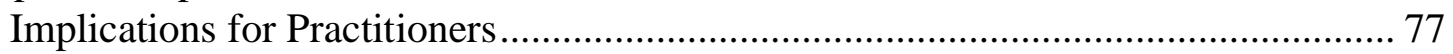

Supporting GTAs at the University Level ................................................ 78

Coordinators Promoting a Culture of Support \& Connection ............................. 79

Suggestions for Overcoming Challenging Situations as a GTA ......................... 81

Taking Time to Rest and Play............................................................. 83

Maintaining Healthy Boundaries ....................................................... 83

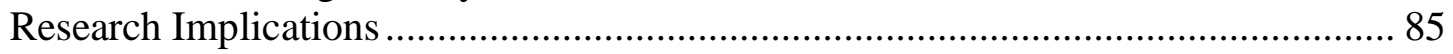

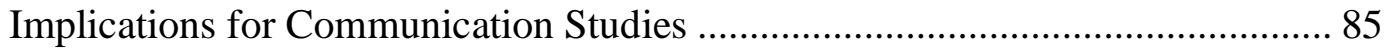

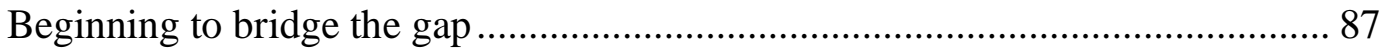

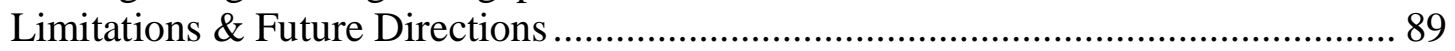

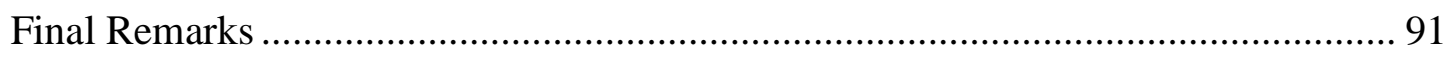

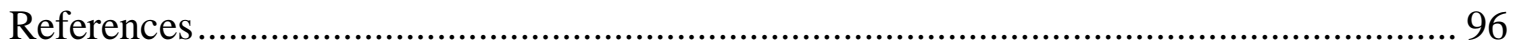

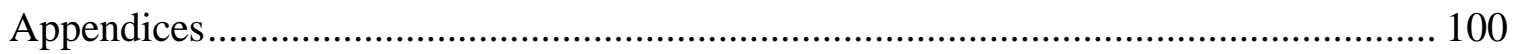

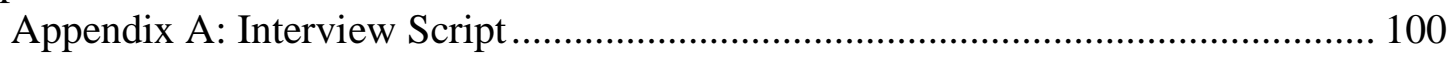

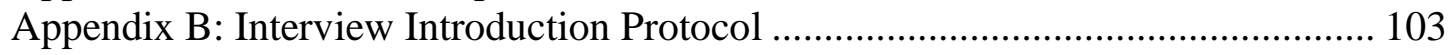

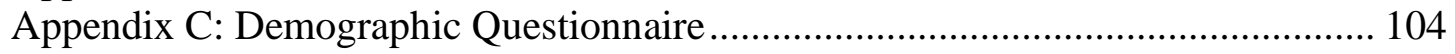

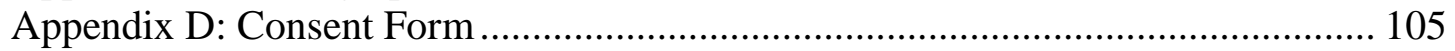




\section{Chapter 1: Introduction}

I can remember exactly where I was standing when I received my acceptance letter. The air was warm against my skin on a day in late April, and I was just a few weeks shy of graduating from college. With the fear of the unknown weighing heavily on my chest, I walked to the library to print out an exam for one of my professors. As I walked through the middle of campus, I overheard some other seniors discussing the full-time jobs they had accepted for after graduation. Friends had backpacking trips lined up, dream internships locked in, or they were moving across the country to begin their careers. It seemed as if everyone around me wanted so desperately to get out of school as quickly as possible. I, on the other hand, had fallen in love with academia. All I wanted to do was immerse myself in the world of communication research and teaching. For the past two years, I had dreamt of becoming a communication instructor, and this dream was on the cusp of coming true. I was waiting to hear back from the one school that could help me bring my dream to life. Phrases such as "you are not what they are looking for" and "maybe they only have room for a few applicants this year" were clouding my mind daily. It was becoming exceedingly difficult to be patient. Then, as I checked my email for the tenth time that day, I found that my aspirations were becoming a reality: I had been accepted to be a graduate teaching associate (GTA) at San Jose State University.

Getting that acceptance felt like winning the lottery. Immediately after opening the email, I found myself smiling like a fool from ear to ear. Once I had finally comprehended what was going on, an onslaught of questions began running through my mind: How was I so fortunate to be given such an incredible opportunity? What would 
my students be like? Was I actually going to get paid to talk about something I love? How many other GTAs would I get to work with? Would they like me? When and where was our training going to be held? What was I going to be like as a teacher? I fiercely wanted to fast forward a few months and get to the very first day of teaching because I had imagined that moment in my head countless times before. At the time, I had only ever been asked to deliver a handful of lectures in communication classes because I was a teaching assistant. I knew that this would be my first time teaching a class on my own. It was beginning to dawn on me that this next step in my journey through higher education would look exceedingly different from all my past assignments and experiences; I was about to take on a new role that would stretch me in more ways than I could have ever imagined.

The day finally came for me to teach my first class, and I found myself becoming increasingly motivated to succeed in this new position of GTA. I spent countless hours preparing for my classes, reading about pedagogical techniques, and planning out engaging activities for my students. Becoming a GTA is a process with many steps; there are so many techniques to learn, papers to sign, and training sessions to attend. The preparation for being hired as a GTA included a week-long training intensive where our GTA cohort listened to a slew of people speak about what was to be expected in the months following our appointment. The amount of information that must be processed in addition to the newness of taking on teaching while being a student poses distinct challenges for GTAs that may or may not be made clear when they go through training. For me, this became more real with each passing week of the semester. 
Even though I was well equipped by my department to handle most of what I would experience in my first few months of teaching, I quickly learned that nothing can truly prepare a new teacher for the abundance of challenges they will face. There were many days when I questioned whether or not I was the right person for the job, and I had to fight some days to remember why I was even teaching in the first place. This feeling is something many of my fellow GTAs said they had continued to experience as well. I watched my colleagues struggle with feeling passionate or motivated to teach, and we were able to turn to each other to process our frustrations. This community proved to be even more essential as we navigated new challenges that none of us could have predicted.

As my first year in the GTA program progressed, my colleagues and I had to face a particularly challenging situation: we had to adjust everything we were trained to do and pivot from in-person instruction to fully online learning in the span of one week when the COVID-19 pandemic began spreading rapidly throughout the world. In March of 2020, President Donald Trump declared COVID-19 a national health emergency, which led to the state of California issuing a stay-at-home order which mandated all residents to stay at home except to go to an essential job or shop for essential needs. Due to this order, students and faculty at SJSU were told we would be completing our coursework and instruction online for the foreseeable future. This challenge has proven to be quite intense and disorienting in multiple ways. For many of us, the state of the world forced us to grapple with things we never had to think about before. We were adjusting to a "new normal" as we made sense of teaching amidst the chaos and disorientation the pandemic had brought upon our personal lives. For many instructors, this time was potentially 
painful, sad, and discouraging as we aimed to transition from our comfortable in-person classes to distance-learning via online platforms.

While those of us immersed in higher education may have thought many times about giving up or calling it quits, many fought to make this "new normal" the very best it could possibly be for our students. In my program, our GTA team had to learn to be flexible in order to provide our students with the best education possible. This process was arduous, and we were faced with many changes that we were not prepared for. Understanding and making sense of one's teaching persona in the middle of a global pandemic has proven to bring about even more confusion for many of us, but it is something GTAs across the nation are working to do. The solidarity we may feel is one small way we are able to work through the discomfort.

Navigating the role of GTA is a continuous process with many twists and turns along the way. The experiences I have struggled through as well as stories my colleagues have shared have caused me to ponder so many different questions: how do GTAs make sense of challenges such as the COVID-19 pandemic? What do they do when they are faced with something they have never encountered before? I am compelled as a researcher to take time to process these questions not only because I am a GTA myself, but because the answers have implications for future professors and the way universities run their GTA programs. These questions have sparked a conversation with faculty members that have pushed me to look into how many people fall into the category of GTA and why this scholarship should be updated. 
As I begin my contribution to the conversation about the GTA experience, I must point out that I cannot separate this research from the context of the COVID-19 pandemic. Everyone taking part in this study has been affected by it in a multitude of ways that may or may not be reflected in the outcome of this research. While GTAs may have their own set of challenges that are considered typical or frequent in their role, the explicit and implicit challenges caused by the COVID-19 pandemic will provide specific insight into how a pandemic can impact the world of higher education. The COVID-19 pandemic caused us to have to learn new techniques for teaching and learning via computer-mediated communication, and it was something that made many people have to rework their training and teaching methods. This has caused us to alter our communication in some ways, and this research will give us a glimpse into how this has happened.

\section{GTA Demographics}

In 2019, there were more than 1.9 million graduate students enrolled in graduate programs in the United States and Canada, and $70 \%$ of those students were in master's or graduate certification programs (Council of Graduate Schools, 2019). The number of students who go on to pursue these degrees is increasing by the year. By 2029, postbaccalaureate enrollment is projected to increase to 3.1 million students (National Center for Education Statistics, 2020). Many students enrolled in these degree programs are recruited to become GTAs to help their departments meet the general education teaching requirements. These students may also be asked to apply for the position because their professors see potential in them and choose to encourage them to do so 
(Smollin \& Arluke, 2014). They spend their time split between teaching, conducting research and taking classes to fulfill their degree requirements. In some universities, such as Purdue and University of South Florida, up to 26 percent of undergraduate courses are taught by GTAs (U.S. News and World Report, 2017). According to the Bureau of Labor Statistics (2018), there were over 135,000 graduate teaching assistants (GTAs) in 2017. The bandwidth needed to train and support all of these students as they teach classes is essential to their success, which can be seen further in the specific example of the GTA population at SJSU.

As reflected in the statistics above, we find that there are a plethora of undergraduates who are currently being taught by GTAs at SJSU. According to the Dean of the College of Graduate Studies, there were 215 students enrolled as GTAs in the Spring semester of 2020 (M. D'Alarco, personal communication, October 5, 2020). This means that there were approximately 6,000 students being taught by graduate students during that semester alone. The rising number of GTAs who are teaching or assisting faculty members in their instruction reflects a need to ensure that these students are adequately prepared for their role. Additionally, it would be helpful to know more updated information from universities regarding the number of students who are GTAs as well as the undergraduate population being taught by these instructors. Statistical information about GTAs should be updated continually, and it would be beneficial on multiple levels to track this information within specific disciplines as well as larger departments such as SJSU's institutional research department. In knowing this information, universities can provide more updated information in their training and seminars. 
Knowledge about the challenges these graduate students face is critical for the future of higher education because of the effects these situations can have on both GTAs and their students (Pytlak et al., 2014; Smollin \& Arluke, 2014). Difficult experiences could have a multitude of effects that could have a ripple effect and negatively impact a GTA's interest in pursuing teaching as a profession as well as their students' educational experience in their course. From this project, I hope to update the current communication scholarship on this specific topic while also providing SJSU with more information about how they can mitigate the negative experiences of these graduate students. I also want to learn more about sensemaking practices and what they look like in the sphere of academia for GTAs. Along the same lines, I desire to learn more about these experiences to give future GTAs a better support system and remind them that they are not alone in their struggles. If the future of the world really does lie in the hands of the coming generations, it is worthwhile to make sure these new teachers are taken care of so they can turn and give their students an education that is worth the investment.

When examining the scholarship surrounding how and why seasoned professors push through discomfort to care for their students, it is clear that GTAs experience this same drive to want to overcome obstacles (Freezer \& Myers, 1997). Angela Duckworth describes this process as having grit. She writes that "grit is about working on something you care about so much that you're willing to stay loyal to it" (Duckworth, 2016, p. 29). Uncovering more information about how this grit manifests in GTAs can help current and future GTAs find solidarity and new methods for working through hardships. The difficult experiences of teaching assistants remain largely untold in the realm of 
communication studies, and the current backdrop of a global pandemic is a strategic time to work towards examining the unique challenges faced by individuals who occupy this role. 


\section{Chapter 2: Literature Review}

GTAs play a multifaceted role in the life of many universities. While both teaching and taking classes at the same time, GTAs are able to gain the experience of being an introductory level instructor while conducting research and earning their degree. If they are assisting a specific faculty member, they are often given the responsibility of grading papers, exams, and other work submitted by undergraduate students (Rhodes, 1997; Teasdale et al., 2019). The university is then able to acquire more employees who they can utilize in their lower-level classes for a reduced price (Payne et al., 2015). Balancing between the different roles of student and teacher at the same time can prove to be a unique challenge for new GTAs.

The process of navigating this tension has been reported to be quite stressful, and this area of research within the realm of master's-level students has not been thoroughly investigated (Payne et al., 2015; Smollin \& Arluke, 2014; White \& Nonnamaker, 2011). GTAs may find themselves overwhelmed with the abundance of responsibilities being handed to them all at once (Mazzola et al., 2011). Although it is valuable to acquire feedback from program coordinators and instructors across multiple departments to learn how to effectively train and support graduate assistants, gathering responses directly from GTAs themselves is imperative for figuring out specific methods for improving programs, training and support systems. In the following sections, I present an overview

of the current GTA literature as well as the topic of teacher resilience to provide context for why the current study fills a gap in communication scholarship. 


\section{GTA Training}

\section{GTA Training in Communication Studies}

Training, mentoring, and supervising GTAs across a multitude of departments can be difficult for universities to manage due to lack of personnel, power, or resources. GTAs end up performing quite an assortment of tasks while teaching introductory level courses, and many schools would not be operating at the current level that they are without these students. Within the past 20 years, GTA training has become much more robust across many communication departments (Fassett \& Warren, 2012; Feezel \& Myers, 1997; Rhodes, 1997; Young \& Bippus, 2008). In these training sessions, graduate students are given the tools they need to be able to administer what has been deemed the "basic course," a class that provides opportunities for lecturers to teach and assess communication (National Communication Association). In the process of researching the seminars and activities in which GTAs are trained, scholars have found that this introductory time plays a significant role in the formation of GTAs identities (Mazzola et al., 2011; Myers, 1995). However, this training is not standardized across departments and some students are left to figure out their potential challenges on their own.

Existing literature regarding the experiences of GTAs largely consists of information about teaching assistant training programs and feelings of self-efficacy for individuals in these roles. These studies have provided significant information regarding the impact of GTA training and how different training models are used to help prepare graduate students to teach introductory courses (Golish, 1999; Young \& Bippus, 2008). Scholars have found that there is a need for GTAs to know how to problem-solve and deal with 
various disappointments that may arise (Rhodes, 1997). Much of this research has focused primarily on the training programs that GTAs participate in and the specific activities that they are asked to take part in as they prepare to take on a new position (Bruss, 2009; Payne et al., 2015). Studies from different fields have found that GTAs experience anxiety and other various challenges surrounding the unknown aspects of teaching a course for the first time (Pytlak \& Houser, 2014; Simmons et al., 2017; Smollin \& Arluke, 2014). This research leads to more questions to be answered surrounding how GTAs overcome these challenges and grow as scholars throughout the process.

\section{GTA Training Across Disciplines}

The training of GTAs from various universities across the United States has been documented in studies conducted by scholars from fields such as communication, sociology, engineering, geoscience, and business (Smollin \& Arluke, 2014; Teasdale et al., 2019). GTAs from disciplines outside of communication report that they experience high levels of stress surrounding their teaching responsibilities and training for their jobs (Becker et al., 2017; Smollin \& Arluke, 2014; Teasdale et al., 2019). Without the proper training to prepare them for their duties, many GTAs report feeling lost and incompetent in the classroom. These feelings can deeply impact the way GTAs perform in the classroom and even how they feel towards pursuing further work in academia (Young \& Bippus, 2008). In order to improve the experiences of current and future GTAs, scholars must be attentive to the difficult nature of this role and empower graduate instructors to 
overcome these hardships by providing them with adequate training opportunities before their first day of class.

While some departments and universities focus on preparing GTAs for different challenges during training, others do not provide thorough training opportunities for new instructors to process through their fears and insecurities (Pytlak \& Houser, 2014; Simmons et al., 2017). The hurdles and overwhelming situations GTAs may encounter can cause them to question their own self-efficacy. For example, GTAs have reported feeling that they are inadequate and begin to question whether or not they are the right person for the job as they start out the semester (Blouin \& Moss, 2015). Teaching a class for the first time or facilitating any part of a college-level course can be daunting on many levels, which is why many departments require GTAs to go through training before being appointed to their positions. GTAs are given varying levels of independence as they work together with faculty members during training to be able to give undergraduate students a worthwhile experience (Payne et al., 2015; Smollin \& Arluke, 2014). This reciprocal relationship between the university and GTAs that is introduced during training can prove to be both beneficial and difficult to navigate (Dannels, 2015; Payne et al., 2015). This relationship can be further clarified as GTAs are given a closer look at what the expectations are for them in their role during the training process.

While it is crucial for these training programs and seminars to be revised and updated each year to be able to reflect the needs of each respective GTA group, this is not where the work ends. The amount of effort that is put into preparing GTAs should be reflected in the work that is done to check in on them throughout the academic year. As we look 
deeper into the experiences of GTAs, it is essential to recognize the value in examining what goes on after graduate students have finished their training. As aforementioned, studies have been conducted regarding the success and effectiveness of GTA training programs and the feedback GTAs provide their supervisors from multiple disciplines. It is significant to look at the lived experiences of GTAs long after the training sessions have concluded because they are responsible for helping undergraduate students across the nation achieve learning objectives and acquire the knowledge they need to move to the next part of their educational career.

Existing literature regarding the experiences of GTAs largely consists of information about teaching assistant training programs and feelings of self-efficacy for individuals in these roles. These studies have provided significant information regarding the impact of GTA training and how different training models are used to help prepare graduate students to teach introductory courses (Golish, 1999; Young \& Bippus, 2008). Scholars have found that there is a need for GTAs to know how to problem-solve and deal with various disappointments that may arise (Rhodes, 1997). Much of this research has focused primarily on the training programs that GTAs participate in and the specific activities that they are asked to take part in as they prepare to take on a new position (Bruss, 2009; Payne et al., 2015). Studies from different fields have found that GTAs experience anxiety and other various challenges surrounding the unknown aspects of teaching a course for the first time (Pytlak \& Houser, 2014; Simmons et al., 2017; Smollin \& Arluke, 2014). This research leads to more questions to be answered 
surrounding how GTAs overcome these challenges and grow as scholars throughout the process.

\section{Challenges in the Academy}

\section{Faculty Resilience}

Resilience has been described as the positive or effective processes in which people cope with trauma or immense difficulty (Brewer et al., 2019; Houston \& Buzzanell, 2018; Schwartzman, 2020). When discussing resilience, it is important to note the critique and limitation of the topic being used to blame the victim instead of focusing on the ways in which social systems hold people down. Resilience in this study is not being used to tell people that it's "all on them" to overcome challenges, as many challenges people face are due to unjust social systems and oppressive policies in place. Resilience should not be acknowledged apart from the effects that power and structure have on the individual as well as the group. In this study, resilience is noted to be a topic of research surrounding the experiences of professors and other people in the realm of academia, so it will be discussed in correlation with that previous research. Much of the scholarship on resilience in university settings is focused primarily on student academic resilience, but it has been found to be a key factor in helping professors manage challenges in their jobs as well (Brewer et al., 2019). Institutions of higher education are sites in which professors go through burdensome experiences that leave them feeling undone and overwhelmed. These individuals experience sustained pressure to perform well and maintain success in their scholarship to be able to keep their jobs. For teachers at colleges and universities, being faced with adversity can be somewhat disorienting and hard to manage when they 
are often the ones who are supposed to encourage their students to be resilient. Specifically, it is reported that the challenges professors face range anywhere from having to counsel students through hardships, dealing with plagiarism and academic dishonesty, feeling like an imposter, balancing work and life responsibilities, and the publish-or-perish mentality that they are pressured into adhering to in their field (Beltman et al., 2011; Gu, 2014; Staton-Spicer \& Marty-White, 1981). These challenges are only a snapshot of what goes on both in and outside of the classroom for many professors, and they point to the fact that there is a great deal of emotional labor that goes into overcoming some of these issues.

Resilience is said to be a key factor in helping both students and teachers manage challenges in higher education. Faculty or professor resilience can be used as an essential tool for furthering research and inquiry, expanding civic engagement, deepening connections with others in the university, and modeling perseverance for students (Schwartzman, 2020). When examining resilient behavior and the communication of resilience within institutions, professors show a combination of a desire to be honest about their own limitations while simultaneously working really hard to persist and grow in the midst of difficulty. This can often manifest in different behavioral or communicative choices that convey flexibility, openness to ambiguity, and even higher tolerance to pain (Schwartzman, 2020). In such studies of these manifestations, it is argued that resilience in communication is an ongoing, active process. It is not something that professors necessarily arrive at or achieve one day, but it is something they must learn to practice with each passing semester. 


\section{Strategies for Overcoming Challenges}

In the process of learning to work through different problems they are faced with in their jobs, faculty members can, at times, overcome these feelings and recover from such complications. While some challenges may not ever be something these scholars can truly overcome, there are certain strategies that have proven to be effective in helping people in these positions prevail over problems. Professors who are able to maintain the course even while circumstances are difficult have what is called high self-efficacy. When teachers feel they are successful at their jobs and students are genuinely learning the content, they feel more inclined to keep working even when things are challenging (Beltman et al., 2011; Houston \& Buzzanell, 2018). Because they believe that they are giving students what they need to succeed, teachers will keep pushing through hard situations because they know that there is some sort of pay off in the end (i.e., the students will learn or retain information, they can grow as scholars, they will be compensated monetarily, etc.).

Additionally, it is found to be the combination of both internal factors as well as external support that empower teachers to overcome the challenges they face with students (Gu, 2014). By creating and maintaining a positive support network with other faculty members, professors find that they have the space to process their negative experiences with people who will understand them (Schwartzman, 2020). This network can be a safe haven for going over potential future scenarios to help instructors navigate how to approach individual situations, but it can be more communal depending on the way it develops. It is said that when communities practice resilience, they work together 
to "address a shared challenge", preparing them to move forward as they adapt to the hard times they are experiencing (Spialek \& Houston, 2019, p. 11). Reaching out to connect with other faculty members can lead to the progression of such networks that will provide solace for the days when teaching becomes too much to bear alone. These relationships can provide insight into certain communicative processes that may foster resilience across more levels than just tenure-track faculty or full professors.

\section{Weick's Sensemaking Theory}

Weick's sensemaking theory comes to us from organizational communication scholarship. This approach to analyzing communication in organizations came out of a turn towards interpretive work in the 1980's. More specifically, the ideas of phenomenology outlined by Husserl and symbolic interactionism as developed by Mead led the way in beginning the conversation about sensemaking (Nicotera, 2020). His explanation of collective sensemaking comes out of his work on the intersection of both communicating and organizing. These ideas were a mold of what he had learned about in regard to cognitive dissonance theory and other work in ethnographic methodology. Weick defines sensemaking as a process of constructing reality in a way that makes certain concepts comprehensible (Weick, 1995). This process is not something that happens on an individual level; it comes out of collaboration with others, and it usually happens through communicative acts. By communicating with others, members of organizations can work alongside each other to "structure the unknown" which helps make certain events sensible (Nicotera, 2020, p. 29). Specifically, we may see this 
happening when members of a group come together to discuss what has recently occurred in order to make sense of what is going on around them.

One particular context in which sensemaking takes place is when people experience a discrepancy between what they expect to happen and what actually happens. Weick describes this as a process in which people assign meaning to these surprising discrepancies after the fact (Weick, 1995). For example, when workers predict that they are going to receive a specific piece of feedback and end up hearing something completely different, they may choose to participate in sensemaking with some of their teammates to figure out why this did not line up. Sensemaking happens not only in the initial interaction and processing of what has transpired, but it is also a social process that is ongoing long beyond the interaction has ended (Weick, 1995). When people engage in these sensemaking conversations, they are interpreting both the verbal and nonverbal communication they have just encountered. Upon interpreting this information, they make sense of what is worth keeping and what should be let go from the interaction. It is through sensemaking that we participate in methods of understanding human behavior.

Sensemaking theory has to do with gathering and sorting various information through social interactions, which is a process that is constantly occurring within organizations. When deciding what to analyze in regard to understanding how a group makes sense of the unknown, scholars may choose to look at the specific word choices or phrases that are used by the participants within their respective workplaces. Communication approaches seem especially well suited to the study of sensemaking given that the process is enacted and regularly articulated through communication behaviors. While originally studied 
within organizations, the effects of sensemaking can be seen within educational settings and teaching experiences as well. Many institutions of higher education function with similar hierarchical structures as formal corporations, and these communication behaviors that occur in the context of GTA programs can give us more insight into how graduate students make sense of negative interactions.

If we look at the university through the lens of this organizational theory, we begin to see this process happening right before our eyes. When GTAs experience difficulty with students and then come together to talk about it, they are engaging in sensemaking. If a group of GTAs experience some sort of feedback session with their supervisor and they text each other about it after the interaction has ended, they are participating in the final step of sensemaking: retention (Nicotera, 2020). This theory goes beyond the processes of explaining such as understanding or interpretation to include elements of action or behavior. If scholars look at the actions of GTAs and how they process behavior collectively, they have a new window into the way GTAs act in challenging circumstances as well as how they may work to fix problems. This theory is helpful for examining how GTAs navigate challenges with students because people often engage in sensemaking when they encounter undesirable situations. By analyzing the communication happening within GTA communities, any data that could be found connected to sensemaking could help scholars understand more about how people process through these undesirable situations alone or in groups. Taking time to see where sensemaking happens in the realm of higher education has the potential to help us create more effective spaces for people to communicate with each other. 


\section{Research Questions}

This study investigates the approaches to overcoming challenges among GTAs in higher education and uncovers the sensemaking process from the perspective of GTAs. For the purpose of this research, the phrases "challenge" and "difficult situations or circumstances" will be used interchangeably to signify anything that GTAs encounter that they distinguish as hard or taxing. These instances may range from tasks that are time consuming, situations that cause worry or stress, or completely new responsibilities that they have been asked to take on in their role as instructors. It is worthwhile to acknowledge that just because something is challenging does not mean it is inherently bad or even painful. To understand how people go through challenging situations, I also intend to ask about how they processed, or made sense of, a challenge. To learn more about these challenges, the study will address the following research questions:

RQ1: How do GTAs communicate about the challenges that they experience?

RQ2: How do GTAs at SJSU make sense of these challenges?

RQ3: What actions do GTAs take to overcome these challenges?

Answering these questions will provide communication scholars with insight into the perspective of GTAs and their sensemaking practices while expanding the literature surrounding this topic. However, finding the answers to these questions could have immediate and practical implications for GTAs and program coordinators as they prepare to navigate the challenging terrain of higher education in the years to come. 


\section{Chapter 3: Research Methods}

When examining the current literature on GTAs in communication studies, it has become clear that the holistic experience of the GTA is often overlooked in an effort to focus on the improvement of training materials and workshops. In an effort to answer the research questions guiding this study and to build upon the past work of researchers who have begun the conversation of sharing the GTA perspective, I have aimed to incorporate more GTA voices into the scholarship in order to understand more of what occurs beyond the end of these training sessions. In this chapter, I will review the sampling and interview processes chosen for this research, and I will provide an overview of the data analysis procedures I used once the data was collected.

\section{Data Collection}

\section{Recruitment}

Due to the nature and involvement of human participants in this study, approval to conduct ethical research was granted from the Institutional Review Board (IRB) from San Jose State University. GTAs were recruited through purposive and known-group sampling. Known-group sampling is the "selection of events from groups that are known to possess a particular characteristic under investigation" (Reinard, p. 447, 2008). Using resources and connections in the School of Graduate Studies, the recruitment for GTAs mostly happened via email; the recruitment script was sent to current graduate assistants across the university through the GTA course on Canvas. By pursuing recruitment in this way, there was a greater opportunity for multiple departments to be represented in this study. 
Additionally, I gathered some contact information of GTA program directors at SJSU who could circulate my research participation inquiry. I asked people to extend the invitation to participate in this research to other GTAs whom I did not know or interact with at the time. I began to approach these individuals via email once I began the data collection portion of this research. Background information on my thesis topic and the research was given in the first email as well as the consent form for them to review before signing in the following email if they show interest in participating. To ensure participants were made comfortable, I told them how long the interviews would take and asked if they would be interested in setting up an interview with me. While I did end up facilitating the majority of the recruitment, others helped me spread the word to those who were potentially interested in participating.

\section{Participants}

All individuals being interviewed for this research needed to be above the age of 18 . This included individuals who were enrolled as master's students in various departments at SJSU who were also GTAs as well as those who have already graduated from their programs. I contacted those who had completed at least one full semester of being a TA, which included a group of current lecturers or faculty members at the university. To recruit people who were GTAs but have since graduated from SJSU, I contacted other faculty members who have the contact information of people who fit this category and asked them to send along the email invitation to those individuals. However, as time went on, it became apparent that many current GTAs were interested in being a part of this study, so after about one week of recruiting, I was able to stop as I had over 15 email 
conversations scheduled with people who were appointed as GTAs during the semester I was conducting this research. I chose who would be interviewed for this research through a first come, first served basis. I interviewed every person that contacted me and continued the conversation upon my response to them. There were three GTAs who were initially in contact with me but never responded upon my second and third response to them. All other GTAs who reached out to me were interviewed for this study.

I ensured that each participant in this study chose to be a part of this research of their own volition through the use of consent forms and by giving ample time to make sure they understood what participation in this study entailed. Each participant was assigned a pseudonym upon their email correspondence with me. I aimed to mitigate any potential conflict of interest by recruiting GTAs from multiple departments across the university, yet multiple people who responded were from similar departments or colleges within the institution. There were no rewards or other benefits offered to those who choose to participate, and what was shared in the context of the research is not to be shared in other contexts.

It must be noted that the participants in this research may not be entirely representative of the population of GTAs at SJSU or in the United States. Because individuals volunteered to share their experiences with teaching and learning, the ideas reflected came from people who wanted to share how to best engage students during a pandemic. Participants may have felt a specific way about this topic based on their understanding of the research from my description and volunteered to share information with me in order to divulge data that they felt needed to be in my report. It was my aim to 
make this project as open and inclusive as possible, and I sought to bring in as many GTAs as were willing to share with me.

While I intended to be as comprehensive as possible, there are still groups and perspectives that are underrepresented in this study which creates bias in the sample. For example, many of the participants mentioned that they were interested in or at least considering going into some sort of teaching or another part of academia in the future. People who had a negative experience teaching overall did not participate in this study. There were also quite a few GTAs from the same departments while other departments were not represented at all. While they are not totally exhaustive, the perspectives shared in these interviews came from individuals who were eager to share about their teaching experiences.

\section{Interviews}

Because of the nature of the world at the time this recruitment began, the methods chosen for this study were the most optimal way to conduct such research. Interviews are considered to be a good choice for researchers who desire to learn more about the lived experiences of participants while also giving space for them to be as open as they choose, making them a logical choice for this study (Tracy, 2013). The flexibility allowed by this type of data collection is an advantageous choice for this project because it gives participants a chance to share their perspectives and respond in ways that bring up pertinent data points. However, there were also some limitations to this process. It was impossible to conduct in-person interviews or to have observations of group meetings via Zoom due to IRB restrictions and COVID-19 regulations. The choice to move forward 
with these semi-structured interviews was the best way to answer the research questions as there was no other way to successfully collect qualitative data during a global pandemic.

If participants expressed interest and a desire to participate, they were asked to choose a date/time to have an interview. After scheduling the interview time, I sent a consent form for them to read and sign electronically. They were sent follow up emails and the Zoom link the day before the scheduled interview. Participants also completed a brief demographic questionnaire electronically at the end of the interview. The interview followed the interview questions in Appendix A and upon its conclusion, participants were given access to the recording of the interview if they indicated that they wanted to receive it. Finally, participants were followed up with and given the opportunity to respond with anything they would like to add, change or update from the interview to be put on the record.

The participants were assigned pseudonyms in order to retain anonymity, to keep the answers to their inquiries separate from their identities, and to protect their confidentiality. Participants were informed of this when filling out their demographic questionnaire (see Appendix C). Participant names and demographic information were kept separate from their responses as well. Only I had access to individual data, and any reports generated as a result of this study will continue the use of pseudonyms when connected to an interview exemplar or artifact description. The interview files were titled "participant interview" when it was placed in a folder. The pseudonyms were then assigned to the video recording or the audio recording. The only places where 
participants' names show up is on their consent forms and on the "key" of participants. I have kept this list of pseudonyms and the consent forms in a separate encrypted document.

\section{Demographic Information}

In addition to the information shared during the interview itself, the demographic questionnaire gave me more insight regarding how long the participants have been teaching as well as which department they work or worked in. There was a total of thirteen participants interviewed for this research. Six of the participants were from the College of Social Sciences, two were from the College of the Humanities and the Arts, and five were from the College of Science. Nine of the participants identified as female, and four of them identified as male. The age range of the participants was from 21 years old to 45 years old, and nine participants had taught one semester while the other four had taught for longer than one semester. Five participants identified as White, two identified as Latinx, one identified as Black, one identified as Middle Eastern, one identified as South Asian, one identified as Indian, one identified as Pakistani, and one identified as Korean. In order to stay as consistent as possible with my interviewing for each participant, I drafted up an interview protocol for the process (See Appendix B).

\section{Interview Questions}

All interviews were conducted via Zoom on a MacBook Pro. I began the interviews by asking the participants a myriad of questions surrounding their experiences as GTAs and what challenges they have had to navigate in their role as a teacher in order to build rapport (See Appendix A). I then asked specifically about how they have overcome 
different challenges and what the process of handling those situations was like for them. It was important that I made sure to ask questions that would adequately answer the research questions, so I chose to mostly ask questions that prompted the participants to recollect their past experiences. This helped me collect data in the form of memories as they themselves remembered them. For research question 1, I wanted to ask questions that would allow for the participants to recall their own past communication patterns that they utilized as they went through challenges. The challenges were not specifically named during this section, as I wanted them to come up naturally and organically for each participant. Some examples of these questions were "what are some of the challenges you have faced as a GTA?" and "how did you talk about that challenge with other people?" Another way I worded this was "when you discussed this with your fellow GTAs or your supervisor, what did that sound like?" or "can you give me a picture of what it looks like when you talk about challenges?" These questions gave me ample opportunities to hear about various ways GTAs describe their own communication surrounding these issues. I chose to ask these types of questions along with asking them to "tell me more about that" in order to give them the space to respond and verbally process things with me if they had not thought through such things prior to our interaction.

To help answer the second research question, I asked the GTAs to tell me about how they "processed through" or "made sense of" challenges. I also used the language of "how did you come to understand what was happening?" as a way to further grasp the techniques they themselves used throughout their teaching journeys. I asked them "can 
you tell me about how you made sense of those challenges, and how you responded?". By being given the opportunity to answer the open-ended questions, GTAs were given a chance to describe their own experiences and how they themselves perceived them. In addition to this, I chose to provide them with hypothetical situations in which they would need to "make sense" of what was happening. These mostly consisted of examples of student misconduct, academic dishonesty, and even personal struggles (See Appendix A). I would frame these questions by saying "in (insert hypothetical situation), what would you have done?" or "has (insert hypothetical situation) ever happened to you? If so, how did you make sense of that?" By asking the participants these questions, I was able to more clearly pinpoint their communicative habits and processes through listening to them describe their past communication and also seeing what they think they would do hypothetically. This gave me multiple vantage points from which I could gather themes and find patterns in the data. By asking about sensemaking in the interviews, I was also asking participants to share their own understanding of meaning in their teaching context. As they took time to talk through their own sensemaking, whether it was recursive or sequential, GTAs could then think more critically about how they understood the coconstructed meaning created within their departments and smaller friend groups.

\section{Procedures}

The interviews were recorded using Zoom's built-in recording feature which allowed me to keep all the interviews saved to my hard drive. I transcribed the interviews using the rough cut of Zoom's transcription as a basis but listened back to all of the audio to refine all the transcripts to reflect the word-for-word responses of the participants. The 
recordings of each interview were not edited in any way. The amount of time spent transcribing the interviews was dependent on the length of each interview. It took me approximately one hour to transcribe 15 minutes of talking in an interview, so it took about 40 hours in total to transcribe everything. I made sure to include any nonverbal responses used by the participants such as pauses, filler words, laughter, and sighs. This is included in some of the responses in chapter 4 because the nonverbal behaviors used in communication can be used to add emphasis or provide insight into the meaning and feelings behind our speech acts (Reinard, 2008).

The digital files were kept in a password-protected computer device and saved to the hard drive. All files that were recorded over Zoom's cloud feature were immediately saved to the computer and placed in an encrypted folder. The folders containing various data elements were also encrypted. As a way to back up the data, the research files also were saved to a memory stick containing all information pertaining to the research as a backup. This memory stick was kept in a locked cabinet that only I, the primary researcher, had access to. Portable devices were stored in a locked filing cabinet when not being used.

\section{Data Analysis}

Choosing to examine themes within the data provides participants with a central voice in the research. The themes present in the responses provided by GTAs will enable their characteristics to be distinguished and connected all at the same time. In the field of communication, these themes are seen as the "building blocks" that are used to highlight particular communicative processes and their connection to meaning making (Owen, 
1985). This provides the researcher with a basic understanding of the subject and context being shared about within the interview. Thematic analysis is a method that invites scholars into the lived world of their participants, and in doing so, makes their worlds comprehensible (Tracy, 2013). Themes represent a "range of interpretations that are used to conceptualize and constitute" the different dynamics present within the communication (Owen, 1984, p. 273). There are likely multiple meanings that exist outside of a theme; however, thematic analysis has a way of highlighting the ideas that participants choose to make prominent.

When it comes to the contents of this study, thematic analysis was used to excavate any patterns that could arise in what participants communicate. Owen (1984) suggests a methodology wherein the researcher finds and highlights three specific types of communication. First, I was looking for and being aware of recurring themes, or similar threads of meaning which are reflected in different words used by the respective participants. After doing my initial coding, I took note of repetition within participant responses, which can manifest as repeated words, phrases or sentences. Finally, I paid attention to forcefulness showing up in the data which manifested as dramatic pauses, changes in volume, or emphasis of a specific idea. Because data such as stories, personal examples, and observation must be interpreted, this method was suitable to analyze it with the purpose of generating themes or codes from the data (Lucas, 2011; Tracy, 2013). Themes were analyzed and evaluated using this method alongside forms of both first and second level coding to synthesize and organize the themes that surfaced. 
Once I completed the interviews with my participants, I transcribed and coded the recordings in order to narrow down specific themes that presented themselves across the interviews. In an effort to allow the data to speak for itself, I went into the data analysis process with an open mind to find what emerged naturally. I chose to do my data analysis using NVivo, a qualitative data analysis software. As I went through the data to complete the first-level coding, I began by assigning parent codes to words, phrases, and ideas that were repeated by participants in NVivo. Then, I went over all of those a second time and built out the codes to more fully reflect the meaning of the words. These came out to be some full sentences, while others remained as shorter words or ideas. After that, I engaged in second-level coding wherein I pulled child codes out of the parent codes to create even more categories. To do this in NVivo, I created an "initial codes" section to reflect the original parent codes just as they were and then added in a second section where I copied and pasted all the same codes which was where I then placed the new child code categories underneath the parent codes. For example, one of the parent codes present in the data was "actions for overcoming challenges" and a child code underneath that was "reaching out to others".

In an effort to fully capture and preserve the codes, I also printed out the finished transcriptions and highlighted themes by hand. In the first round of this, I highlighted the themes using color-coding, assigning different colors to specific themes. Then, I went through the process a second time looking for areas where I may have missed certain themes that were forceful and repeated by the participants. Finally, once I had a list of the themes I see within the data, I sent the participants the list and had them look over them 
to review the information for accuracy. This gave me the chance to change any areas where I misunderstood or misrepresented anything the participants were aiming to communicate in their responses. This form of data analysis allows for things to arise within the data, and it made a way for the data to be examined so I could begin to grasp a deeper comprehension of what the participants had experienced as well as the context in which they were each coming from. I did this in order to help the participants understand and contemplate their own challenges as they made sense of the ways in which they have overcome those situations. 


\section{Chapter 4: Results}

Below, I will review the themes that emerged from the interviews. To provide context and a deeper understanding of the themes themselves, I have included examples of participant responses. The three research questions provide a framework for the findings. In the first section, I explore the ways in which GTAs communicate about challenges, how they describe their own communication, and how they communicated their challenges to me during the interviews. It is valuable to situate the sensemaking of such challenges within GTAs' own communication and description of their experiences to understand how they perceive challenging situations. These descriptions of communication are complex and multifaceted in that the participants shared more than mere explanations, and I will report this as well.

Next, I will examine how GTAs model sensemaking in their interactions with various people as they process their experiences, including how they made sense of potential challenges I gave to them to work through with me during the interviews. The participants were able to think through their own sensemaking and then talk about how they understood it with me in the moment. In the third section, I identify the actions the GTAs in this study take to solve problems and overcome challenges they report facing in their roles. Within this final research question, I also provide information from participants on how they situated themselves within challenges that are ongoing and may not be able to be fully overcome. 


\section{RQ1: How do GTAs communicate about the challenges that they experience?}

In order to answer this first research question, I asked GTAs a number of questions that would help them come to an understanding of their own past and current communication techniques. When asked the question "how do you communicate?", six of the GTAs I interviewed found themselves a bit perplexed as they tried to answer. They paused, looked a bit puzzled, and even had a moment of hesitation before responding. How does one describe the way they talk about things? It takes a certain amount of introspection and self-awareness to be able to formulate an accurate understanding of how we communicate with others. As they answered this question, three GTAs mentioned that it is helpful to have another person tell them how they typically communicate in order to feel that they adequately understood their own communication skills. For Hayley, this question required a lot of thinking and even a few long "umms" before she responded with “...that's a hard question. I don't often think about how I talk about things." However, as time went on, they began to open up more about how they talked with others about challenges throughout the semester.

When asked to describe how the experience of teaching has been overall during a pandemic, GTAs shared in their own words that they felt "it's been challenging, stressful and nerve-wracking" and "it was just so, so stressful, so overwhelming, that it really, like, affected my health physically." By sharing more about the potentially less exciting parts of their experiences, GTAs chose to be open with me and discuss the good and bad that came along with their jobs this year. As mentioned above, talking about challenges could sometimes lead these participants to feel like they were going to be judged. It may be 
easier to not talk about the dark side of the role of GTA, but these GTAs chose to do so willingly.

GTAs talked with me about their communication surrounding challenges in various circles they were a part of. Depending on the situation they were in, GTAs found it to be difficult to share about the challenges they faced in their own personal lives. For Lena, this was heightened because it was somewhat uncomfortable to bring up her personal life in a workplace context. She shared that there was pressure for her internally to not fully communicate how overwhelmed she was: "I think when it came to communicating those challenges, either like, consciously or otherwise, I undersold how stressed I was or overwhelmed I was, because I'm naturally the person who has it together in most of my circles." This pressure to not be forthcoming with the stress and challenges they were experiencing kept GTAs from talking about their situations at times. Lena, along with two other GTAs, mentioned that when talking about challenges, it felt as if their credibility was being put under a microscope or that they could be considered as "weak" in the eyes of others. A lack of vulnerability and a desire to seem to "have it all together" as a teacher can keep GTAs from disclosing their struggles with others in higher education. In order to not be questioned or judged, GTAs could choose to only share certain aspects of their struggles instead of being more vulnerable. This concept of not wanting to always share everything about the challenges they faced may have caused GTAs to not be as candid with me in the interviews.

When it comes to how GTAs communicate about their experiences, there were two different levels of communication present in the data. Specifically, there are patterns 
when it comes to how they communicate about challenges - the type of language they use and how they contextualize the different problems they have faced. There are layers of how they talked with me about their own communication, also known as metacommunication, weaved through many of the answers from participants. This choice to discuss their past communication was a time of reflection for the GTAs in this study. Additionally, the participants also described who they discussed challenges with while they were going through them. I will unpack both of these ideas separately.

\section{GTAs Engage in Honest and Open Communication}

Primarily, interviewees mentioned that they communicated about challenges by using open and honest communication with each other and their supervisors. For example, Michel told me this about how she communicated with her students during the semester:

Excerpt 4.1: I'm very open

I'm also very open with my students as well if they come to office 01 hours and if they have any questions or problems or concerns, um, 02 and we talked through it, I think I'm very open with them just 03 about how I feel as well as an instructor, because they do 04 understand that I'm also a student as well. We all go through 05 challenges. (Michel, GTA in the College of Sciences) 06

As we see in this quote, Michel shows that being open and creating a space where people can talk about challenges was valuable to her. Being open means being willing to talk about things and discuss issues that may not always be brought up. Similarly, honesty for GTAs meant being forthcoming and straightforward, or "not beating around the bush or sugar-coating things," as described by Lane. By being open, GTAs are reflecting that talking about challenges is not a bad thing or something anyone should be ashamed of. 
Nine of the participants shared about specific instances where they themselves as well as their supervisors and colleagues communicated honestly and openly chose to do so. Participants defined "open" by saying their communication was "direct and to the point" (Bec), "just being honest" (Danny), and "very straightforward with how we communicate" (Jeremiah). All of the interviewees agreed that discussing their challenges and communicating about them either while they were going through the challenge or after something had been resolved was beneficial to them. Caroline explained it like this:

Excerpt 4.2: A bunch of communication

I found it super important to just have a bunch of communication 07 with other teachers. So, you know, like with our GTA team, our 08 group chat, and just asking each other questions, because I think a 09 lot of times, yeah, we have these questions are like these 10 problems, but then if we're not actually talking about them, then 11 we're all dealing with them independently and we might be like 12 trying to reinvent the wheel, like we're all independently trying to 13 make solutions. (Caroline, GTA in the College of Social Sciences)

Like Caroline, nine other GTAs mentioned that having people to talk to and bounce ideas off of was a great way to know what to do next. They mentioned texting their fellow GTAs or reaching out to set up a time to connect on Zoom. This was helpful as they chose how to navigate future challenges in their positions.

The way in which many participants explained their own communication surrounding those challenging experiences was describing it as open and honest communication. For example, as mentioned above, participants would share a story or challenge they faced and describe it to me by saying that it was "hard", "stressful" or "difficult" for them at the time. The words they used reflected a level of transparency, and they did not shy away 
from describing the strenuous parts of their teaching experiences. In doing so, they were modeling for me the same openness they had with their students as well as within their departments, as seen in excerpts 4.1 and 4.2 .

More importantly, this idea of being open and honest about struggles overlapped into their descriptions of conversations with others. In fact, participants mentioned that they found it to be most effective to get straight to the point and be transparent when discussing issues with other members of their teams and their departments. When asked about how they discuss challenges, Bec shared this example:

Excerpt 4.3: Words aren't minced

I try to just think, you know, what are the facts? What are we 14 looking at? And what's going on? And luckily our director feels 15 the same way and so does our administrative coordinator. And I 16 would even argue that most of the professors feel that way too, 17 because when we have faculty meetings, like, you know, words 18 aren't minced. If somebody is unhappy with something, we're 19 going to say it. And, um, I think a direct style of communication, $\quad 20$ of course, with respect and tact, you know, you don't want to 21 offend anybody...So I think we're direct, but in a very respectful 22 way. (Bec, GTA in the College of Humanities and the Arts)

From this perspective, we see that there are some communication practices regarding challenges or problems that are fostered and supported by members of the departments which these GTAs are members of. By being in a group of other instructors who were clear about issues that they were experiencing, GTAs could do the same and speak openly when they faced similar issues. Another example of this came from Michel, who mentioned her tight-knit relationship with their supervisor and how she was able to discuss difficulties in the meetings they had each week: 


\section{Excerpt 4.4: Ask my supervisor}

My main support is my supervisor, so we usually meet once a 23 week. Um, and during that time we talk about what worked for me 24 and what didn't or any struggles that I'm having. So, if I have any 25 questions, um, whether, if it's, if I don't know how to deal with a 26 certain student's situation, then I will ask my supervisor for help. 27 (Michel, GTA in the College of Sciences)

By being able to be open with their supervisors weekly, GTAs have the space to discuss the challenges that arise with people who will know how to advise them to move forward. This space to talk about struggles was echoed by ten other GTAs as being an extremely helpful part of their experience. Another GTA mentions that it is both the nature of the communication (clear, open, honest) and the frequency of it that makes a difference. Jeremiah states "I really am not shy to talk about it (a challenge) with the course director and my fellow TAs. This is something that we talk about, I want to say on a weekly basis, but realistically, it's more like on a daily basis." These examples of being consistently open provide GTAs with the opportunity to ask questions and receive feedback on what to do in challenging situations from their program directors and coordinators. It is not something that they feel they must hide; they are open about it with each other and those who supervise and support them.

\section{GTAs Describe Their Feelings}

Over half of the GTAs I spoke with chose to tell me about how they were feeling as they encountered strenuous situations in their roles. For five of them, discussing feelings was not something that they report as being a primary way of communicating about hard things in their role as GTAs. For the other nine, this was one of the ways they chose to communicate about challenges, and they chose to describe these feelings to me as I asked 
them about what they had been through. One participant said this to me when she was discussing her past feelings:

Excerpt 4.5: Wearing my heart on my sleeve

I just felt like my heart, you know, my heart, I was wearing my 28 heart on my sleeve. I was, you know, I really care for this student, 29 and I really wanted to see him be successful. And, um, and I really 30 wanted to help him. (Chrissie, GTA in the College of Social 31 Sciences)

In her explanation in the excerpt above, Chrissie expressed that she felt like her feelings were constantly in view as she helped her students. By wearing her "heart on her sleeve", she was letting her students know how she felt about them. She was not holding back or trying to hide the amount of care she had for them. Lena had a similar experience as she taught a class for the first time. She shared with me that she would "tell her students how she was feeling" as a way to help not only connect with them, but to talk with them about hard things going on in the world that were challenging to process. As illustrated by these examples, being transparent with how they are feeling is a way for GTAs to communicate with others about the challenges they are facing and even invite them into their world.

When it comes to the exact feelings they had experienced, GTAs reported a mix of different emotions. Some specific feelings that came up for many participants included feelings of stress, anxiety, and experiencing feeling like an imposter or that they were just "faking it till they made it", also known as imposter syndrome. When Bec was telling me about how she felt during the semester and how she would talk about her own experience of feeling like an imposter, she mentioned that she would ask herself "what do I even have to offer?" and that "it's like sitting on my shoulder every time I even start a class". She shared this with her colleagues and even her supervisor. These feelings of not 
thinking they are good enough or that they are not the right person for the job were echoed by two other GTAs as well. Lena mentioned the idea that she did not know why she was chosen to be a GTA, and that this was a topic of conversation with her and some of her teammates. However, these were not the only feelings that participants discussed with me.

Others described more specific situations where they felt things such as strong care for their students, a desire to affirm that they were not alone, and feeling like they needed to fix problems as quickly as possible. When certain students would open up and share about their personal lives, one participant mentioned that she struggled with knowing what to do and feel in her role, as seen in excerpt 4.6.

Excerpt 4.6: Stay within my role

Those pose challenges for me as well because, um, I felt like I 32 needed to stay within my role, um, as an instructor and not 33 necessarily take on some of the other stuff that was happening. $\quad 34$ And so, I utilized, um, the system a lot where I would refer them 35 out to an academic advisor or a counselor, or, um, you know, $\quad 36$ somebody was struggling with, um, food insecurities. I would let 37 them know about the food pantry and, um, some of the support $\quad 38$ systems that we have embedded in the college. (Hayley, GTA in 39 the College of Science)

Here, we see a GTA leaning on the "system" in order to give students what they need and aid people while simultaneously trying to navigate their own role. In moments like these, some participants mentioned feeling a struggle within themselves of wanting to help their students, but also wanting to keep some sort of distance between them and their students as they completed their own coursework. This account from Hayley's experience shows that there is a feeling of wanting to not go outside of the bounds of the role while also helping students in the process. Madison described this challenge in the following way: 
Excerpt 4.7: Hold their hand

Because we kind of built this relationship, there were students $\quad 40$ who I've had to work hand in hand with and hold their hand $\quad 41$ through this whole semester just to get them to a passing grade. $\quad 42$ Um, because they were going through so much and they are 43 freshmen, maybe? I don't know, but they're still learning how to, 44 how to go through a college experience like this. So, um, it was 45 kind of like, it felt like a sister or a mom kind of role, like a 46 parenting role. And it was a lot of nurturing, I guess. (Madison, 47 GTA in the College of Social Sciences)

As excerpt 4.7 illustrates, GTAs had to work with their students and nurture them as they figured out how to be in college, some of them for the very first time. GTAs are placed in numerous situations that they could not possibly prepare for and choosing to reflect on their own feelings together and alone was reported by participants to be immensely helpful for their own growth. In their conversations with each other, they would talk about their feelings as a way to validate each other. By sharing how they felt about certain challenges, they could work together to make sure they were doing things correctly. For Danny, this meant running things by his fellow GTAs to make sure his feelings were accurate. He shared, "I would just kind of express how I really hope that I'm not wrong about this...talking about the similarities on the exams and trying to feel like someone could back me up and confirm that I'm not wrong about it" when I asked him more about a challenge he had with the exams he gave in his classes.

\section{GTAs Pose Reflective Questions to Themselves}

In addition to describing their feelings outwardly to their colleagues, GTAs also engage in intrapersonal communication about challenges, or communication with oneself about what is going on. Caroline shared with me that she often has an internal monologue 
going on inside her head as she tries to understand what is happening (or not happening) in her class: "am I doing a horrible job? Like, am I just a terrible teacher? Am I even able to do this?" By asking herself these questions during class, she is working through communicating about challenges within herself. While other participants do not ask the same exact questions as Caroline does, they seem to share the same "reflective questionasking" process that she employs. These questions range from general inquiries such as "what do you do?" to even more specific, such as what Hayley asks herself when students turn in assignments late: "How can I grade the student? And you know, how do I deal with their assignment? Do I let them turn it in really late?'. These questions show us that GTAs care about learning from their experiences and understanding how to approach different situations as best they can.

One specific example of how these questions may also be products of the larger societal situation that GTAs are navigating was the question that came up for many GTAs while teaching during the COVID-19 pandemic: how do we get students to keep their webcams turned on during online class? This was reported to be a constant struggle and cause of stress for three individuals. Participants mentioned asking themselves things like "why don't they talk?", “could we get training on how to encourage that (turning webcams on during class) to happen?" and "what am I supposed to do in those situations to encourage that?" The idea of trying to get students to turn on their cameras came up in almost every conversation I had with participants. While not all participants mentioned these sorts of questions pertaining to webcams, most of them did communicate to me that they know they have grown because of the challenges they have walked through, and 
they look forward to using what they have learned in the future. These internal questions were a portion of the discussion regarding challenges for these GTAs, as were their interpersonal conversations with their colleagues.

\section{GTAs Discuss Challenges with Other GTAs}

All GTAs who I interviewed for this study mentioned how valuable it was to be in communication with others about challenges both as they were happening and after they had overcome certain hardships. One of the most consistent responses when asked who they would talk to about their challenges was the other GTAs within their department. For the sake of maintaining coherence, I will adopt the language that participants used to describe their fellow GTAs and refer to groups of GTAs within departments as "teams". Only one GTA, Michel, reported their supervisor as being the person they communicated about their challenges with the most. All the others shared that they mostly discussed challenges with their GTA cohort members. For example, people mentioned having conversations with their GTA teams during weekly meetings about what challenging experiences they were having. Sarah even shared that her supervisor provides them with the space to process through such challenges verbally together in their meetings. This gave her time to talk it out with some other new instructors to see if anyone else had gone through the same thing. One participant put it this way:

Excerpt 4.8: Stay within my role

When we talked, it was almost, like, weekly. We would kind of 48 check in with each other, like, 'how are your students doing?', 49 'How are you doing?' It was almost like a weekly check-in and 50 that would give us a chance to talk to each other and, you know, $\quad 51$ encourage each other to do whatever that right thing might be. $\quad 52$ (Lane, GTA in the College of Science) 
Like Lane, two other GTAs mentioned that it was because of this level of communication with their teams that they felt they could handle or tackle new challenges with students or situations that they had never been placed in before. This theme of communicating consistently with their fellow GTAs about challenges they faced came up continually for many of the participants. Caroline explained how talking about challenges in the context of the team is actually a great way to mitigate any future problems that could arise from lack of communication. She says:

\section{Excerpt 4.9 Asking each other questions}

I found it super important to just have a bunch of communication 53 with other teachers. So, you know, like with our GTA team, our $\quad 54$ group chat, and just asking each other questions, because I think a 55 lot of times, yeah, we have these questions or, like, these 56 problems, but then if we're not actually talking about them, then $\quad 57$ we're all dealing with them independently and we might be like $\quad 58$ trying to reinvent the wheel, like we're all independently trying to 59 make solutions. (Caroline, GTA in the College of Social Sciences)

This idea of talking with other teachers to get feedback and insight into others' solutions made a way for Caroline to not have to reinvent the wheel while also supporting her fellow TAs. It was stressed to me by a few of them that they felt as if talking through the hard parts of their job with others was the only way they believed they would get through them. Jeremiah described the process of unpacking challenges with his team as "really what drives us to be able to go through these challenges together. I mean, we talk it out. I'm not shy to, to email or text my colleagues. They always reach out to me as well." Without having other GTAs to lean on during a global pandemic, many of these participants believe they would not have been able to get through some of the harder days. While most GTAs mentioned their communication with other GTAs as being the 
most consistent channel through which they discussed challenges, the other group of people they shared this information with were their students.

\section{GTAs Explain Challenges to Their Students}

As the participants reflected on going through some very unusual and stressful situations during the course of the previous semester, they shared with me that one specific avenue in which they chose to communicate clearly and directly was in conversations with students. GTAs in this study mentioned that they wanted to have a spirit of "transparency" with their students and a level of openness so that they would all learn to trust each other. Chrissie mentioned this when describing how she would handle things when she was struggling with some aspect of online teaching in the middle of class: "if I was in a situation where I didn't understand certain technology aspects, I would ask them. I'd be like, 'Hey, you guys all know how to do this. So help me out here." Another participant mentioned not always agreeing with the instructions for various assignments they were being asked to facilitate in the course, and he shared that "just being honest with the students, I guess, has definitely helped me with a lot of the challenges I faced.”

Many participants chose to share the struggles they experienced with their students, and they found that in turn, some students became more willing to be open with them because of that. This can also be seen in a story Hayley shared with me about when she was displaced from her home because of the California wildfires: "And so like dealing with that, I just told my students right off the bat, like, 'hey, I'm displaced right now. I know what it's like to be in a situation where, you know, you could struggle with your 
living situation." This level of honesty was something that some participants mention not always experiencing from their own instructors, and they took it upon themselves to communicate more openly about such things as they continue their own development as instructors.

While this openness was not always easy for all the participants, it was still brought up as a method for communicating about their own challenges. Lena, for example, shared with me that she initially struggled with telling her students that she needed more time to grade one of their assignments. She said it was particularly hard because "it was like admitting a failure to them." However, choosing to tell students about different difficulties, whether they have to do with teaching, grading, or their personal lives, is an effective way for GTAs to share part of who they are with their classes. It is an arena for opening up about struggles, things that are not as neat or flashy on the surface, and the other areas where they feel they have overcome or triumphed in some way. Participants agree that it is better to just be honest and upfront about things with their students instead of trying to pretend that they never have problems whatsoever. This humanizes them in a way that participants mention is vitally important for establishing trust and a classroom environment where both the students and the instructor can bring their true selves every single day.

\section{GTAs Process Through Situations with Outsiders}

It can be tremendously insightful to talk with people who are going through the exact same experience as you. However, it is also valuable to get some insight from people who are not directly related to the problem you are trying to deal with. For GTAs, there is 
an obvious need to balance their work and life responsibilities in a way that helps them maintain their success. This often looks like having people to talk to who are from outside of the GTA program or group they are a part of, and it could also consist of people outside of the graduate program entirely.

Many of the participants mentioned specific people whom they process different challenges with who are outside of the program entirely. Danny mentioned that he really loves to debrief and process through things with his roommate, who really does not understand what the class Danny teaches is all about. He shared that "I would talk things through with my roommate sometimes about like upcoming assignments or something that I would have to teach" as a way to share about the struggles of balancing both teaching and learning in his everyday life. Bec brought up the same idea when she shared this with me as some advice for future GTAs:

\section{Excerpt 4.10: Generate a support system}

Create a support group outside of both being a student and being a 60 GTA, like, you know, don't make your support system, the same 61 people that are in your master's project team or the same, you $\quad 62$ know, because that's going to generate a lot of conflict inside, 63 whether you want it to or not. It will. Um, so I would say generate 64 a support system and hobbies that take you out of both of those 65 roles. (Bec, GTA in the College of Humanities and the Arts) 66

Others brought up how helpful it was to tell their family members about what was going on in their classes if they had a rough day. Over half of the participants gave examples of talking to people in their lives who had teaching experience as a way to help them frame their own issues they were having in the introductory college courses that they teach. Caroline mentioned talking to her mom, saying: 


\section{Excerpt 4.11: Generate a support system}

I would tell her about all the things like I'm doing this and I'm 67 doing this. And she was like, your college class is more interactive 68 and fun than my elementary school classes! Um, well maybe not, 69 but she encouraged me to think that way too, based on her years of 70 teaching. (Caroline, GTA in the College of Social Sciences)

This same sentiment of having parents listen to their problems was echoed by Michel, who was the only participant to not mention discussing her challenges with any team members. She said her primary support network was her parents, friends and her supervisor. Having conversations with these groups about her struggles was the main way she verbally processed how to overcome such challenges. Having the space to talk about how they are affected by situations with students, how they felt their own teaching was going, and the ways the job was stressful with confidants outside the immediate GTA context provided participants with the chance to get some fresh perspectives. This was, as Lena put it, "a refreshing time of reflection".

\section{RQ2: How do GTAs at SJSU make sense of these challenges?}

Sensemaking, the practice of ordering the world around us as we exist in organizations alongside others to be able to act in it, often helps us handle the challenging situations we are faced with in our jobs. This process is happening constantly - it happens in large corporations, non-profit organizations, and even institutions of higher education. People experience change and are presented with new or unusual challenges almost every day as instructors and professors. This is the reality of the ever-changing world of academia and coupling it with a global pandemic is a recipe for sustained sensemaking. 
As I ventured deeper into the discussion about challenges in general and how they chose to communicate about such experiences, I began to see Weick's sensemaking framework on display as I listened to the participants describe what was said when processing through their challenges in dyadic or group contexts. This section will outline how GTAs chose to explain their own past sensemaking as well as the "in the moment" or "on the spot" sensemaking they went through during the interviews. Both of these responses will be weaved into this section of the chapter. Sensemaking is something that organizational members engage in as a way to reduce uncertainty, and in a time of heightened unpredictability, sensemaking became one of the grounding practices for the GTAs that participated in this study.

For GTAs, sensemaking begins as we learn how to be scholars in the academic world. In this study, the Western context provides specific meanings for GTAs when it comes to what type of behavior they should display as instructors. In some cases, we reenact these meanings and ideas we see displayed by our supervisors. In others, we may begin to challenge the status quo if we find that something we have made sense of does not sit well with us. For the GTAs in this study, sensemaking happened for them in the three different stages outlined by Weick: first enactment, then selection, and finally retention. Five of the participants mentioned these happening in sequential order, while the rest of the GTAs described the same steps, but just in a different order. Their responses for each stage of sensemaking will be outlined below. 


\section{Sensemaking through Enactment}

To begin, we must break down the sensemaking process in its entirety. The first step in organizational sensemaking is enactment, also known as the step in which environments are created. This is also the space where individuals begin to perceive and formulate how to act upon the changes they will experience in their workplace environment. For most GTAs, this enactment begins the moment they begin their training. Four of the GTAs mentioned how training was a constructive process where they felt like they were gaining knowledge they needed to be able to proceed forward in their roles successfully. They described this using phrases like "training was where we learned more about what to expect" and "training helped me be prepared". They then would go on to enact the environment as was described to them in their training. Some also brought up that this stage was crucial for them in beginning to build relationships with others who they would later call upon for support and even grow to love as dear colleagues and friends. Madison was the most expressive about the enactment stage in her interview responses. She said:

Excerpt 4.12: Find the right people

I think I had to find the right people within our GTA team to 71 really have people who understand what exactly I'm talking $\quad 72$ about...finding people who are willing to be there for you. Um, 73 and once I found those people, it was really easy for me to open $\quad 74$ up and talk. (Madison, GTA in the College of Social Sciences)

For Madison, the place where she began enacting her role was in the training sessions where she found people she could trust. Reflected in what she says in line 68, she was able to open up and talk more once she found the people who would understand her and 
help her enact her role as a GTA successfully. This stage of "finding" began for many of them during their training. With much of the training process delivered completely asynchronously for nine of the participants who had just begun teaching during the pandemic, the enactment stage for new GTAs proved to be an interesting start to understanding of what the norms were within their respective departments. Some participants mentioned how they began their time as GTAs feeling "inadequate" or "not quite sure" about themselves yet, which reflects Weick's idea that sensemaking is not some arbitrary process; it is a "matter of identity" (Weick, 1995). By taking time to reconcile one's own identity with what they are being asked to do as a teacher, the process of sensemaking really begins to take off. As GTAs figured out what it is they would be doing in their jobs early on, they began the process of sensemaking before they even taught or facilitated their first class.

Additionally, enactment would happen for GTAs in their interactions with their students. Since this was occurring in moments when participants were processing new or challenging situations, GTAs reported back to me what this was like retrospectively. Bec told me about how she went about the initial enactment of understanding how to handle plagiarism with one of her students:

\section{Excerpt 4.13: Looking at it contextually}

Um, so the way we handled it was we gathered the evidence, we $\quad 75$ brought it up to our director to make sure she was in the loop. $\quad 76$ Then we asked the student, "Hey, did this happen? Did you use $\quad 77$ this material?" and um, the student did in fact plagiarize. Um, and 78 the way that it was handled was basically we explained that we $\quad 79$ understand that this happens....um, so it was a lot of looking at it $\quad 80$ contextually, right? We couldn't just look at it and write it off as 81 just a blanket plagiarism, you know, event. We had to really take 82 
into account the emotional stability of the student, what they're Humanities and the Arts)

Looking at this excerpt, we see all of the sensemaking stages at play. For the enactment portion, Bec talked about gathering the evidence and understanding the context of the student's situation. For her, this was a moment where she was creating an environment for her students to understand how she would handle issues of academic integrity. Other GTAs had similar instances with their students where they would enact an environment with their communication. Sarah told me about how she would explain to her students what she was thinking if they asked a question she did not have an answer to. She said, "I would explain to them that I would take time to think about that question and get back to them...this gave them a chance to see that our classroom was a place where people didn't have to know everything." Here, we see a teacher enacting what they want to be a norm in their classroom. Sarah is telling her students that she does not know everything, and that it is okay to take time to think through things before responding. By modeling this type of environment, GTAs can help their students learn more ideas about what their teacher will do in class and what they can expect in such situations.

In their descriptions of how they made sense of different challenges they faced throughout their teaching experiences thus far, GTAs mentioned how they enacted different ideas in their own classes. GTAs explain this as being a time to "establish connection" with students, help students know their instructor supports them, and create a space where students could be honest with them about their own learning. Sarah mentioned that she began to make sense of her role "once my supervisor showed me 
more of what my everyday tasks would be like...and this gave me a set of guidelines". These initial moments of setting the tone for the rest of the semester became the baseline for what some GTAs would think about when there were any sudden changes in their class dynamics. In order to know something was off or something needed to be made sense of, GTAs need to grasp what some of the "norms" were for their particular class.

In addition to their own training experiences and their classes, GTAs also brought up how they would begin to enact certain behaviors as instructors only after they had spent time processing through different challenges on their own. This process was described to me as a balance of both thinking through things deeply on their own time, and then bringing those topics up to others later on once they had some ideas or questions in mind. In order to fully grasp the environments that they were creating in their departments and with their students, participants mentioned needing to spend time making sense of what was happening on their own, or in a "solo environment" as Persi called it. By starting off enacting something by themselves, GTAs were able to come to their fellow TAs with ideas of how to make sense of, or select, the environments they were co-creating together.

When engaging in enactment during the hypothetical scenarios I gave them during the interviews, participants mentioned the role of referencing past conversations with their colleagues as well as their supervisors as they figured out the norms. Sarah told me that she would think back to what she learned in training when I asked her what she would do if she was faced with an issue of student misconduct in the classroom. She shared, "I would take time to think back to what my mentor taught me before doing anything else...I 
know I have been trained to handle situations like that without freaking out." In a similar fashion, Lee mentioned that he would "try to do what my supervisor would do" in a situation that he had never encountered before. While these hypothetical situations may be easier to make sense of proactively, both Sarah and Lee reflect that their training experiences play a role in how they enact their responses to uncertain situations in the classroom.

\section{Sensemaking through Selection}

After receiving an initial introduction into the context in which they would be operating as GTAs, participants began their selection processes: the part of sensemaking where members of an organization or group label their experiences and decide what should be dealt with to formulate what they should remember and what they can let go of in the next stage of the process. Selection usually begins when people realize there is some sort of change or uncertainty in their organizational context. GTAs mentioned trying to make sense of what happened, and they often interact with one another to interpret what the changes mean. This included asking themselves questions or going to their supervisors to ask them what they should do. For some GTAs, this started happening shortly after they concluded their training. The selection process would happen in cases where GTAs felt like they were experiencing something different than their perceived expectations for how things should go. For example, Persi explained to me what happened for her when she realized there were some elements of the program that did not map onto her expectations: 
Excerpt 4.14: Challenging the status quo

I think a lot of it was like asking, but like before I even brought it 85 up to anyone, because it was something I noticed early on of just 86 feeling...I felt like this could have been better prepared, but even $\quad 87$ before I shared that with other people, I definitely think I like $\quad 88$ asked myself like, well, what is my role as a GTA? How much is $\quad 89$ expected of me? Like, what is the norm, I guess, because like, is $\quad 90$ me asking for more, is that something that's, in a sense, 91 challenging the status quo? Like, am I challenging what GTA, 92 what teachers, what professors, what they're expected to do? 93 (Persi, GTA in the College of Social Sciences)

Here, Persi is selecting which parts of her experience she believes are ones she was adequately trained for. She spent time thinking through the role she was placed in and asked herself questions about whether or not what she was thinking was challenging the status quo, or if she was off base for thinking that things should have been better. The questions that came up for her were more than just about the enactment of the personal environment that would be created during their time as a GTA; the questions extended to include challenging the status quo and selecting her own understanding of what she should do. As they began to select certain responses and behaviors as they had to communicate about challenges, some GTAs found themselves wanting to. They did not believe that what they were receiving or hearing was the only way things could or even should be done. This points to the noteworthy idea that GTAs might not always enact the same environments as they are taught to. They have the agency to be able to question and push back on the training they have received and ask for it to be improved. This, too, is part of their communication about challenges. By pointing out how things could be made better, GTAs are playing an active role in the implementation of new training practices in their respective departments. From this example, we can see how GTAs may choose to 
start the selection process on their own intrapersonally before turning to others to figure out what it is they need to interpret.

In addition to asking themselves questions about specific situations that happen in the classroom, we can see that GTAs also were thinking about the bigger picture of the GTA experience and teaching in general. Many of the participants mentioned having certain expectations prior to beginning their instruction, and some of these expectations were met while others were not. One participant shared the way she was feeling after learning more about how to teach from just doing it herself. She shared this:

Excerpt 4.15: Do the experience

Um, so at first I was really upset because I thought the training 94 wasn't as great. I'm like, oh my gosh, like, I don't know anything 95 going into this teaching thing. Like, what am I going to do? I 96 didn't learn anything about what I'm supposed to be teaching. And 97 I was really upset. I started to ask my coordinator about what I 98 should do, but after a while I learned that you can't train someone 99 to do that. You just kind of do the experience. Um, and you go in 100 and you learn from it. And that was the training itself. (Sarah, 101 GTA in the College of Humanities and the Arts

In this excerpt, Sarah shows that she wanted to reduce the uncertainty of her experience by talking with her supervisor, but the real selection happened for her once she started teaching on her own. It was in the moments of learning for herself how to handle each situation that she began to understand how to be a teacher. This "learn by doing" approach to selection was echoed by Danny and Lane, who mentioned having to try things on their own in order to see how students would react. By working to reduce uncertainty through moving forward and trying things out even if they did not know 
exactly what to do, GTAs reported being able to find their own rhythm for how they wanted to teach.

In the hypothetical situations I presented to the participants, they mentioned how they "would go to my supervisor" to figure out what to do if students were engaging in academic dishonesty. They also discussed how they would text their group chats and talk about what other GTAs had done in the same situations previously. Madison told me about how she would "check in with the GTAs who had already taught for one semester or even one year" so she could hear a couple of different perspectives. Indeed, many of the GTAs I interviewed shared that they believed their hypothetical responses were very consistent with what they reported having done when they encountered struggles in real life. While selection is a meaningful step in the process of making sense of the world, GTAs chose to mostly discuss how they retained different information or how they think they would do so in a given situation.

\section{Sensemaking through Retention}

This portion of the sensemaking process is arguably the most important. During this time period, people discern which elements from the past selection phase are worth holding onto and remembering for the future. For example, if a GTA has a negative interaction with a student and then brings that up in their meeting with a supervisor, they will likely get into the retention phase during the end of the meeting where they begin to figure out the answer to the question "what should I take from the interaction, and what should I leave?" It is during this stage that the role of the other people engaging in communication with a GTA about the issue becomes highly valuable. Those outside of us 
have the ability to see things from a different perspective; they can provide us with fresh insight and help us see where we might be fixated on certain things or where we need to care more. Because sensemaking has to do with interpreting new and surprising information, it is natural for GTAs to want to talk to their fellow cohort members, their program or course coordinators, or even the department chair about challenges they are facing. When we experience something that is different than what we anticipate, especially if it is more negative than we were expecting, we may find ourselves coming to others to see if they had the same things happen to them.

For GTAs in this study, the retention they participated in was done in community with people that they trust, and it was something that they mentioned they would do when I presented them with hypothetical situations wherein they did not necessarily know the "right way" to respond. For example, I asked each participant to share what they would do if they were faced with a challenge related to student misconduct or academic dishonesty, and every single one of them mentioned that they would either go to their supervisor or talk to their fellow TAs. The types of retention questions that they would ask included "what is the proper protocol for this?", "what have students said to you when you caught them cheating?" and "what would you recommend I do next time?" This was something they mentioned they would ask when they talked with their supervisor, pointing to a desire to figure out what they could bring with them on into the future interactions they have surrounding issues of cheating and plagiarism. This question in particular acts as a way to guide GTAs as they formulate an action plan for future interactions. They figure out from their superiors what they should care about and what 
they no longer need to be worried about. Hayley specifically brought up how her teammates had gone to the class coordinator to discuss what should be done with a student who evidently cheated, and she shared that if that were to ever happen in one of her classes, she "would probably do the same thing". She went onto share exactly what the retention process consisted of for her colleagues by mentioning that "they looked at the rules and everything, and just kind of went over it like actually the policies and everything, just to make sure that they were doing it correctly" before moving on with what they knew they wanted to keep from their interactions with each other and the students. These examples of retention have led me to document even more examples of sensemaking practices at play in these conversations. For those who are not familiar with this theory, the idea of processing information or interpreting the uncertain elements of the world around us can seem far too simple. However, the nuances within such a communicative practice require even closer examination.

\section{Retention Practices}

When it comes to exactly how these GTAs chose to make sense of and interpret what was happening around them, they disclosed a wide range of practices that they engaged in throughout their time teaching. In order to reach the point of retention, communicators must first select which interpretations of new or surprising information they plan to subscribe to. Many GTAs chose to focus on the last section of sensemaking with me: retention. After pulling all of the sensemaking ideas together and examining them closely, a few themes stood out from across the departments represented in this study. These will be unpacked below. 
One of the most frequently brought up practices was the strategy of asking questions. More specifically, this concept was brought up most frequently in regard to the challenges of student interactions. GTAs reported that they would not only ask questions of themselves, as mentioned above, but they would look to their fellow graduate students to help them interpret the uncertainty they were facing. For example, questions like "how should I go about this differently?" or "did I handle this correctly?" were asked amongst a number of the participants. Sharing these kinds of questions with each other proved to be an act of vulnerability because of the need to open up about areas where one was questioning their decisions, or as one participant put it: "potentially not doing things right". By acknowledging that something felt off or something needed to be fixed, participants ventured further down the road of seeking to understand the interactions they were having daily. This openness created a space for GTAs to come together and help each other feel less alone in their feelings of failure, misunderstanding, and confusion. For some, this space to ask questions of each other became the primary and most comfortable format for making sense of the challenges they faced.

Asking questions to each other was a way for participants to be exposed to other perspectives and insight into how others might handle a similar situation as the ones they had asked about. Inquiring of others' teaching approaches, the way they had handled cheating in the past, and even how to respond to emails were mentioned as topics that participants needed assistance with as they taught extended and clarified their understanding of how to interact with their students. These questions had a variety of purposes and motives behind them, such as the clarification of what options could be 
pursued for students who were struggling or figuring out the best way to move forward with a student who had cheated. While these questions might have looked or sounded different depending on the department, one goal remained the same for almost all participants: being able to better understand, care for, and teach their students.

These types of inquiries did not stop with other GTAs. Many participants mentioned that they would mostly try to engage in sensemaking with their supervisors. Some even mentioned this practice as being their go-to in moments of confusion or stress. These types of questions included things like "can you help me figure out what's going on with my class?", "what are our options when a student cheats?", or more broadly "what would you do in this situation?" to give GTAs more of a holistic view of what they could do next in their respective classes to move forward with their students. By asking these questions to people with more experience teaching, GTAs shared that they were able to take significant pieces of advice from the responses they got from their coordinators. Michel shared this when discussing how she makes sense of challenges with students in excerpt 4.4. By talking with her supervisor whenever she felt confused or lost, she was able to figure out what to do moving forward. This example along with the stories from the other participants provided helpful direction for GTAs that they found invaluable as they navigated their first- or second-time teaching courses at the collegiate level. Having someone to back them up and answer whatever questions that might arise throughout their appointment confirmed for many participants the unwavering support they had in their supervisors. 
GTAs interactions with those in positions of authority over them can help illuminate the nature of the sensemaking process for those who are beginning their journey of teaching at an institution in this role. Sensemaking, as explained earlier in this chapter, begins with the process of enactment: GTAs begin their time teaching not knowing what to expect in every situation, and therefore, many of them choose to reenact what they see modeled to them by their superiors. So, in reaching out to ask their course coordinators or GTA program advisors what they should do in certain challenging encounters with students, it is almost as if they are seeking out the "script" from someone who knows it well. The people they are asking seem to have more of the answers. As professors who have years' worth of teaching experience, supervisors know more about how to handle things such as plagiarism, students with severe personal issues, and what to do when students are not participating in class. GTAs learn how to be teachers, scholars, and mentors from the perspective of the faculty members assigned to guide them. It is within these relationships that much of the sensemaking process takes place.

GTAs also mentioned various approaches that their supervisors would take with them as they were going through the selection and retention stages of sensemaking. For example, Bec mentioned different techniques her professor would take when she had any issues come up with specific students in the classes she was teaching:

Excerpt 4.16: Just let it out

Like I have the freedom to just let it out. And it stays between 102 myself and the professor because we have that kind of dynamic, 103 um, and vice versa. She also, when she encounters a problem that 104 she herself needs to vent out, she comes to me too, and we kind of 105 sit down and brainstorm it and see, "Hey, what are our options?" 106 (Bec, GTA in the College of Humanities and the Arts) 
By being able to be fully open with her professor, Bec feels comfortable asking her about what she should do next in situations, and her supervisor feels the same way about Bec. This provides a space for Bec to share what is going on while simultaneously helping her professor. It is, in a way, a reciprocal relationship wherein both parties are able to talk through ideas openly without fear of what the other person might think. This openness was echoed by Jeremiah, who described his relationship with his supervisor like this:

Excerpt 4.17: We just work so closely

I mean, there's not really anything that I'm scared to discuss with 107 my course director. I don't even, I feel it, I feel like it's weird 108 calling her my boss or my supervisor. We just work so closely that 109 it's almost like she's a colleague, even though she's got 20 or 10, 110 20 years more experience than I do. (Jeremiah, GTA in the 111 College of Science)

This excerpt reflects how this openness to be able to discuss things freely with a supervisor can be empowering as it keeps the channel of communication open for GTAs to be able to continually process their selection and retention within the context of their conversations with superiors.

\section{RQ3: What actions do GTAs take to overcome these challenges?}

When challenges arise in life, we can often work through them to be able to learn and grow. While we might not always "overcome" certain challenges or be able to say we conquered them entirely, we can learn to live with them and reframe our understanding of hardship as we practice resilience. There is no shame in the struggle. There is an opportunity to learn about ourselves and how to better support those around us. This was the message that the participants of this research study left me pondering after our zoom calls had ended. As I sat there alone in my office after finishing each interview, I was 
able to breathe a bit easier knowing that these were the type of people teaching undergraduates at SJSU. It was so comforting to hear about how they had gone through hard things, and I found myself feeling so encouraged as I listened to these unique instructors share about how they took action to work towards better situations for themselves, their fellow GTAs, and their students. These actions can be larger, more noticeable approaches to working through challenges, but they can also be much more than that. Striving to overcome challenges can be something that is done in the small, every day, and mundane tasks that are required of us. It is sometimes in these covert, more subtle moments where we slowly and steadily learn how to handle the tumultuous things thrown our way.

As mentioned in the previous section on sensemaking, some of the responses that followed processing through a challenge were making and finding peace with the fact that some things cannot ever be fully solved. The GTAs in this study spoke with me about how they felt like they were still working through things and aiming to see how they can learn from different problems in order to become better instructors for their students. They mention that "it's still happening" for them or they "don't really ever fully arrive" as instructors, which reflects a certain amount of humility present in these scholars. The way they communicated with me about this state of realizing that they might not ever overcome certain aspects of teaching showed me that they are still "in process". They do not believe they will ever stop learning and growing, and this excites many of them. As they went on to explain how they felt they had actually overcome some challenges, they also shared how they plan to work with the other types of challenges that 
may always be part of their experience. Below, I will outline the various strategies and actions they shared with me.

\section{GTAs Sit with the Challenge}

Over half of the GTAs told me that one of the very first things they do when they are faced with a challenge or a problem is to just "sit with it" before moving on or taking any other action. This time of reflection gives them a space to figure out what they perceive to be the main issue at hand, and it can help them reframe and gather their thoughts before taking it to another person. Bec summed it up this way:

Excerpt 4.18: A more philosophical approach

I do tend to sit with it for a little bit, not too long. Um, but I do sit 112 down, and I do think of the bigger picture. I do, I think maybe take 113 a more philosophical approach to a lot of the problems, um, that I 114 encounter, and I try to zoom out and see what the bigger picture is. 115 Um, so I would think, and I don't know if it's a tool, but I do a lot 116 of introspection whenever a problem or a challenge arises. (Bec, GTA in the College of Science)

This excerpt shows Bec trying to think about the challenge before moving into what she plans to do. By taking time to pause and think about the larger context of what she is experiencing, she is giving herself time to make sense of the issue on her own. In pursuing introspection before discussing the challenge with a supervisor or in the context of their GTA teammates, participants are giving themselves the space to go through the selection process of sensemaking in order to communicate this clearly once they do talk with other people about it. When reflecting on this in the moment during the interviews, this process of "taking a step back" or looking at a challenge from a "bird's eye view", as Lee called it, was highly recommended by many GTAs. They feel that without this step, you might accidentally say something outlandish or something you do not intend, causing 
the unfiltered information to be communicated unclearly. Persi described her method of thinking through and sitting with a challenge before taking it to her team this way:

Excerpt 4.19: A more philosophical approach

It's always: identify the problem, identify the source of the 118 problem, do all the work of thinking it through figuring out 119 solutions and stuff. And then from there getting feedback from 120 other people and then from, with all that, the feedback and my 121 own intellectual labor, then coming up with my actions, $\quad 122$ essentially. (Persi, GTA in the College of Social Sciences) 123

Here, Persi provides almost an exact definition of Weick's description of sensemaking, complete with the final step of action. When GTAs engage in sensemaking, some of them are propelled to take action in order to solve the problems set before them. For many of these graduate students, the first step in taking action is a small action in and of itself: taking a step back and accessing the situation before moving forward with what might be considered to be more direct action. The actions that usually followed such analysis included reaching out to those within their communities to help spur on further action.

\section{GTAs Lean on the Community for Support}

Not surprisingly, the most common action taken by GTAs in this study was to reach out to members of their community for support. The number of stories from GTAs about how they leaned on each other and their supervisors or course coordinators during challenging times was overwhelming. During a time in life where people lived through social isolation and had to adapt to changing educational needs almost daily, the need for community was made even more apparent with each challenge they faced. Chrissie described how her teammates and professor helped her overcome various challenges by remarking: 


\section{Excerpt 4.20: The support network}

I think mostly just having the personal support, the GTA's and I 124 think just knowing that and having our professor be our backbone 125 or be our backing to what we were going through was really 126 helpful. And just knowing that we had that support network of one 127 another, and also, I feel like having each other's phone numbers so 128 that we can just randomly text, "Hey, how do I do this?" And then 129 somebody would always answer. So it wasn't like, um, like if you 130 need an answer right away, we didn't have to make a phone call. It 131 was just a simple text message. And most people were happy to 132 help each other out. (Chrissie, GTA in the College of Social 133 Sciences)

Having group chats, email chains, and open channels on other communication platforms proved to be crucial for GTAs to stay connected and fight feelings of isolation as they were teaching during the midst of the COVID-19 pandemic. Danny mentioned the fact that he would text one of his fellow GTAs almost every day. He said if he could tell other GTAs a piece of advice, it would be to get someone's phone number and "ask for support whenever you feel like you need it, or you're not sure what the right move is". This method helped Danny and numerous other participants figure out a plan of action for tackling hard situations with students. By having another set of eyes on the problem, GTAs are able to cipher through different ways of handling it that they may not have ever thought about otherwise. Even though being together was not an option for GTAs during the past year, they still found ways to get together virtually and be there for one another during difficult times. They said they would try to take advantage of the time they had in their weekly meetings with their supervisor, and some of them even mentioned getting together on Zoom randomly throughout the week when they needed extra support. When people have established a level of trust within their small group teams, they are able to be 
transparent with one another and table their own hardships to be able to help someone else.

In addition to the support from the GTAs working alongside them, participants mentioned how helpful their supervisors were as they came across situations that they had never been faced with before. As mentioned briefly above, Chrissie found her supervisor to be the "backbone" of the whole operation. Professors placed in charge of these GTAs were also thrown their own mix of challenges, yet they sacrificed themselves to be able to support these new instructors. Without the mentorship, intentionality, and consistent communication from these program coordinators, GTAs in this study would not have had the tools they needed to move forward with the challenges they faced in their roles. However, stopping there would not have been enough; GTAs also needed to bring things up to their students directly in order to overcome some of the other challenges they mentioned in their interviews.

\section{GTAs Go Directly to Their Students}

One common response when I asked GTAs to describe the actions they would take to overcome the various challenges they shared with me was plain and simple: talk to the students. While this may seem somewhat straightforward, it was much more of a complex decision for some people as they weighed the options of how to act. Because these young professors were new to teaching the courses they were assigned, many of them did not want to sacrifice any of their credibility. When it came down to it, participants believed that one of the most effective ways to begin to fix certain issues or 
figure out what they could do to solve problems they were having with their students was to be forward about things with them.

For example, many GTAs mentioned that they struggled with having students cheat in their classes. In addition to talking through the options they had for moving forward with their supervisors, they would bring the questions to the students themselves. Danny told me this story about his experience taking action after he had caught students cheating in his class:

Excerpt 4.21: Present the evidence

And so basically, I just emailed the students, told them what I 134 suspected them of and then asked if they would like to set up a 135 meeting or talk over email because you're supposed to kind of 136 present the evidence to them and then give them a chance to 137 explain themselves. And usually, they just would respond over $\quad 138$ email. Um, and a couple of times they admitted it and then we $\quad 139$ kind of just decided what to do. Um, and otherwise I would, if 140 they denied it and just wanted to talk over email, I would kind of 141 send screenshots of some of the examples of cheating that I 142 thought I saw, um, and see if they had any other explanations. 143 (Chrissie, GTA in the College of Social Sciences)

While having to handle students cheating was not a challenge experienced by everyone who was interviewed for this study, this process of thinking through a situation of academic dishonesty was presented to each of them. Every GTA in this study mentioned going directly to the students with the information they had acquired and working through that situation with them in the event of cheating or plagiarism. For Bec, Hayley, Jeremiah, Michel, and Danny, this was something they had directly dealt with in the past semester before the interview. 
Along similar lines, participants also shared their strategies for taking action when students were seemingly unresponsive or had stopped communicating with them entirely. This particular type of situation was coined by Caroline as the "ghost students", or those who seem to fall off the face of the earth and no longer show up to Zoom class. To handle this, GTAs brought forth more techniques for communicating clearly and quickly to be able to draw in those students who seemed to be on the fringes. When asked about what actions she had taken over the past three semesters of serving as a GTA, Michel shared her approach:

Excerpt 4.22: Reaching out to students

Um, for the students that had a couple of missing assignments or 144 seemed a little more lost. I reached out to them personally and just 145 sent them emails. Hey, I'm checking in. Um, you're missing lab 146 six. Is there anything you don't understand? You know, I'll still 147 accept it. You know, I really wanted them to pass the class, but 148 not without doing some of the work, you know? Um, so reaching 149 out to students personally seemed to help a lot. (Michel, GTA in 150 the College of Science)

By not letting those students slip through the cracks, GTAs maintained a relationship with people who might have otherwise given up on their class work. By speaking directly to them or emailing them specifically, Michel and other GTAs learned how to better overcome the challenge of engaging those "ghost students". This sentiment was equally as important to Lane, a GTA who found that consistently checking in with students could help him bridge the gap of communication that had grown between students and teachers due to the COVID-19 pandemic. He shared that the regularity of checking in with students and giving them more of his time was the action that made a difference for his students: 
Excerpt 4.23: Ask the students

So, what you can do is you just ask the students continuously, you 151 know, questions, send out announcements, more questions, you 152 know, it doesn't take that much time out of your life to do an extra 153 office hour a week. It's not that much time. (Lane, GTA in the 154 College of Science)

Lane sees his time as something he can afford to give more of to be able to assist students who need help understanding more of the course content. He makes that time to be able to listen to them share about what is going on in their lives, and this action has proved to be quite beneficial for mitigating the challenges of not having students interact or engage or have the support they need to do well in his class. For Madison, pursuing a similar action of giving up her time to help her students feel more understood became something that was monumental for her class. By holding additional zoom meetings and practice sessions outside of her class's normal hours, her students were able to share their struggles, get academic help, and feel more connected to the class as a whole. While this option of reaching out to students and giving of themselves even more became a strategy for some GTAs, there was also a sense of wanting to be like the professors who came before them lingering in the back of the minds of others.

\section{GTAs Utilize Professors and Mimic Their Responses}

Modeling responses and observing teaching styles to match those of their own instructors was a common topic touched on in my conversations with these GTAs. Not only did many GTAs mention that they had strong relationships with their supervisors, but they also had a well of knowledge to draw from that their professors had given them. Whether this came from their time in undergrad or during their graduate program 
experiences, the professors that had helped guide these participants along their educational journey gave GTAs examples of how to handle difficult situations. Not only were these instructors teaching their students who would go on to teach themselves the class content, they were simultaneously modeling how to manage a wide range of issues.

Chrissie shared with me just how helpful her past professors had been and how she would often observe them in their own teaching roles to learn how to pick up on some of their approaches to handling challenges. She mentions that when she came upon something that she had never had to deal with before, the next step would be "observing other colleagues and other professors and how they do that", which ended up being particularly helpful for moving forward in certain situations. In particular, the action that was reflected to Chrissie as she watched her own professors handle hard things was less about taking verbal action, and more about listening to students. She told me that "seeing other professors and how they take that step back and how they really listen for understanding and clarity rather than offering information" helped her shift the way she chose to handle conversations with students. Instead of being quick to speak, she became quicker to listen.

Like Chrissie, others echoed this same sentiment. Jeremiah shared that his own supervisor was actually a professor of his prior to him starting the graduate program, which made their bond even stronger. After studying under the professor for so long, it almost seemed to become second nature to use some of the techniques that had been modeled to him for years. One example of this was how to handle or call out academic misconduct happening in the classroom. Both Jeremiah and another GTA interviewed in 
this study brought up that the action that they would take immediately to address student misconduct would be to speak calmly, but let the student know that they had done something wrong. This, they let me know, was how their own professors handled the situation when it presented itself in the classroom. There was reassurance for them when they reflected on the way in which seasoned professors chose to speak about such problems, and this reassurance made a way for them to act accordingly when they went through similar situations. For both Chrissie and Jeremiah, the way their own professors conducted these somewhat uncomfortable conversations gave them a script to follow if needed and the courage to do it themselves.

\section{GTAs Take Time to Look After Their Own Mental Health}

The intense amount of stress and anxiety felt by GTAs was brought up in more than half of the interviews I conducted. There is something about the role that causes people to feel an immense amount of pressure at times, and it can become easy to stop caring about oneself when you have anywhere from 20 to over 100 students to worry about. Participants that vulnerably shared their own experiences of being overcome with stress and anxiety in their job as instructors or assistants made it very clear that there became a point when they could no longer let things continue the way they were going. They needed to take time off or get some space in order to come back to their grading, lecturing, and emailing with a refreshed sense of desire to keep doing the work. This feeling of overwhelming stress hit Madison in a powerful way during her first semester as a GTA. She shared that in order to do her job, she had to take "mental health breaks". She told me how she came to utilize such a strategy: 
Excerpt 4.24: Mental health breaks

I remember at one point in the semester, or actually a couple of $\quad 155$ times, I was just super drained mentally, physically, emotionally. 156 $\mathrm{Um}$, and I had to take the entire weekend away from the computer 157 away from, like, everything. Um, just because it was just so, so 158 stressful, so overwhelming, um, that it really affected my health $\quad 159$ physically. So I had to take a lot of mental health breaks.

160 (Madison, GTA in the College of Social Sciences)

Madison was not alone in feeling this way, nor was she the only GTA I spoke with who chose to step away from their responsibilities at times to take care of themselves. Persi and Lena also shared their experiences of needing to "walk away" from their grading and lesson preparation in order to feel rejuvenated and more like themselves again. It would be interesting to look at why this role causes people to feel such high amounts of stress and what could be done to help alleviate this in the future. Perhaps, as some of my participants noted, there are aspects of the GTA experience that will never fully be "overcome" but that people just learn how to manage. For a number of these individuals, managing their stress required taking these types of breaks.

As a GTA myself, I began to wonder: what do GTAs do during such breaks? What types of rest or activities do they engage in to help remove some of the stress to feel ready and well enough to return to their computers? For people like Jeremiah, these breaks were times to "take a step back" and do the things that he loves. Whenever he felt stressed, he said that he would make sure to do things that bring him joy:

Excerpt 4.25: Just live my life

I always be sure to space out some time in the day, do something 161 that I like doing, whether it's play a game, talk to my roommates, 162 watch a movie, anything like that, maybe during the week, work 163 
or watch a show instead of a movie, just so it's a little less time $\quad 164$ consuming. I never robbed myself of that. I never, I never forget 165 to just live my life. (Jeremiah, GTA in the College of Science) 166

This notion of making sure to continue to live life was shared by Lena, who mentioned that sometimes it became difficult to separate her work, teaching, and studies when things became hectic. She shared that she would take breaks in the day to do something that made her happy so she would not get bogged down by everything on her never-ending todo list. Other GTAs shared that in addition to doing things they loved, they would also take more time on certain school assignments or even ask for extensions if they needed them. The concept of "taking more time" for themselves was echoed by Persi, who even shared that she had to cut down on her hours at work when she became a GTA because it had become too hard for her to balance everything. She said that it got to the point where she realized: "I was so burnt out, like, and I just started missing class...and so I was like, okay, even though I thought I could do this, I can't. Um, and so I had cut back my hours". Taking time for their own mental health, even if it meant taking fewer classes or working less hours at their other jobs, was a popular way the GTAs in this study chose to handle feeling stressed and overworked. As Jeremiah put it so eloquently, we love what we do as GTAs, "but it doesn't have to be all that we are". 


\section{Chapter 5: Implications}

This research has done more than merely teach me about myself or the GTA community; it has implications for the future of GTA research, mentorship, and training as well as sensemaking within these contexts. The work presented in chapter 4 suggests various implications for research and application within scholarship as well as the higher education system which will be outlined in this chapter.

\section{Implications for Practitioners}

Primarily, this study has provided us with a framework for practitioners: GTAs, GTA program coordinators, and instructors to use as they move forward with teaching in a post COVID-19 world. These interviews have provided insight for both GTAs and their supervisors as the world continues to change and develop. The data have given us a glimpse into some of the more demanding parts of the GTA position, but more importantly, they have given us a look at what GTAs need to successfully make sense of what they experience in their roles. The support they have received and the need for consistent communication with people from their community have been the cornerstone for GTAs in this study as they correspond about challenges, make sense of them, and move forward. First, I will share action steps that could be taken from a university-wide standpoint that could help facilitate sensemaking and community building. Focusing on the aspects of support and connection, I will then outline how these findings can impact the future of GTA programs across our university and beyond. Finally, I will share some suggestions for how to overcome challenges for GTAs specifically. 


\section{Supporting GTAs at the University Level}

Although most of the GTAs in this study found their support within their respective departments, many of them mentioned that it would be even more helpful to have more interaction with GTAs from across the university. SJSU did have university wide GTA training opportunities during this past year for graduate students to engage in via Canvas and Zoom. These events and training sessions were not mandatory, so it really is up to the student to decide whether or not they want to attend. However, it could be helpful in the future to promote these events and trainings even more to ensure all students know about them and are able to attend or watch different training sessions later on. Michel, a GTA who was unaware of the campus wide GTA training, mentioned that "I think overall there, we should have some kind of course or just an orientation of what's to be expected as a GTA or what kind of challenges you might come across and how to deal with them." Specifically discussing common challenges faced in the role during these sessions could provide GTAs with an idea of what they may encounter. If GTAs do not seem to be participating in such events, it could be beneficial to invite guest speakers to attend GTA meetings within various departments to be able to have more personalized conversations about discipline-specific topics or issues. Some sort of resource with "frequently asked questions" about the GTA experience could be helpful to send out to all departments with answers and contact information for people who could further discuss such topics. Finally, as mentioned above, many GTAs struggled with their own mental health issues due to the COVID-19 pandemic and other factors. It would be helpful to make some mental health resources available specifically for GTAs as well as a way to guide them to 
SJSU's psychological services when needed. There could also be some sort of check-in or office hours hosted by the College of Graduate Studies with different mental health professionals. By showing GTAs that they matter at a university level, GTAs can begin to feel more fully supported in their positions.

\section{Coordinators Promoting a Culture of Support \& Connection}

GTAs experience changes that leave them feeling confused, overwhelmed, and nervous, and one way to provide assistance to them during these times is to give them opportunities to connect with those who can walk alongside them during a challenge. We need people like our supervisors, department chairs, fellow GTAs, and even other instructors in our departments to help us traverse the unknown and uncertain situations we encounter. All of the participants in this study continually brought up the immense value of the relationships they had with either their fellow GTAs or their supervisors. This finding causes me to question: what about those individuals who did not feel supported? While this study was as inclusive as I could make it, we must remember that there is a likelihood that GTAs who felt a lack of connection or support from their teams might not want to be interviewed about their experiences. However, what was found in this study does support previous research that has been done on community support of GTAs during their time teaching (Blouin \& Moss, 2015; Feezel \& Myers, 1997; Young \& Bippus, 2008). We need to not only feel supported, but we need sustained connection and interaction with people who are going through similar struggles. This was evident in participant responses about how they would turn to their friends in the cohort to not only help them figure out solutions to problems, but also to just be a listening ear. The specific 
challenges faced by GTAs during a worldwide pandemic made this need to support and connect even more apparent.

As GTAs continue to need to learn how to not only teach via online learning platforms such as Zoom and Canvas, they will also have to be prepared to tackle the challenge of what teaching will look like as our society begins to rebuild and morph after enduring a worldwide pandemic. Without the support of that community and the connection with others who are going through the same situations, GTAs may feel isolated, lonely, and begin to question whether or not they can do their jobs. Chrissie shared "using the support network of other GTAs was really helpful and asking them to help guide me through whatever process I was working on" was something that she knew she could count on when things were tough. Danny said it was important to "definitely ask for help when needed" because there were people in his cohort who could step in and support him when he had no clue how to handle a situation. Without having established connections with people in the GTA community, these spaces to process through challenges with people who know what to do are very rare. GTAs need to be able to call on others when they feel lost or completely confused and find people who will help them navigate the problems that arise as they go through their various duties.

For GTAs to have this type of support and connection, their leaders must model this and facilitate opportunities for them to build relationships with one another. Participants shared that their coordinators provided them the space to talk about things that had happened throughout the week or month that were challenging so they could then discuss those things together. Jeremiah even shared that this was always the first part of their 
meetings; these "vent sessions" were not only how he and his team verbally processed hardships, but it was how they became more bonded through their shared experiences. Others mentioned that they appreciated when professors and mentors were candid about their own struggles as instructors. Lena shared that it made her feel "so much better" to find out some things that her own GTA coordinator had gone through as a new teacher. We need this time to not only connect with each other, but to be reminded by those who are a bit ahead of us in the teaching world that things can get easier and that it is okay to not have everything figured out.

While over half of the GTAs in this study mentioned the value of having support from other GTAs, there were a few individuals who did not have the same support from their peers. Michel, for example, did not interact with any other GTAs during her appointment. The main support network she had was her supervisor, whom she relied on heavily. Without this support system in place, people like Michel would have no real resources for assistance when faced with challenging situations. Establishing and maintaining open lines of communication with GTAs is something that supervisors can do to ensure their teams are able to work through challenges and solve problems.

\section{Suggestions for Overcoming Challenging Situations as a GTA}

GTAs in this study shared ways they need support and how future GTAs could be further empowered to tackle whatever comes their way. GTAs communicate about challenges by talking to others and getting support from them as we engage in sensemaking. Talking with others seemed to be the action most GTAs decided to take to overcome challenges. However, the information my participants chose to share brought 
forth much more than just that answer. They provided me with pieces of advice that could be offered up to future generations of GTAs struggling to overcome similar obstacles. This can be seen in the pieces of wisdom such as Bec's comment to "generate a support system and hobbies that take you out of both of those roles (student and teacher)", Caroline's tip for GTAs to "have a bunch of communication with other teachers", and Danny's idea he wished he could tell himself before he became a GTA: "it's probably impossible to know what the right move is and every situation as a TA, so you should definitely ask for help when needed.” Asking for help, creating community and talking with other teachers are just a few of the ways people chose to work towards overcoming the hardships they faced. These tips can work as springboards for future GTAs to make healthy decisions that will help them flourish in their roles, and they can guide GTA program coordinators in their planning as they prepare for incoming GTAs to join their programs.

While my participants did not bring up resilience specifically and I did not dive into the topic more deeply beyond what has been previously researched, it is an important thing to remember as we reflect on the implications of this work. Often, we may be tempted to put all of the burden and the responsibility on the shoulders of the GTAs themselves to overcome their struggles and press on. It can be somewhat easy to ignore the role of the system and how that affects the true resilience and adaptability of someone like a GTA at a university. There are so many systems in place on national, state, and university levels that affect GTAs and their lived experiences, yet they are expected to "overcome" and deal with these situations. While this study does not speak to this 
specifically, it is vitally important to note, and it would be a wonderful route for a future scholar to take when extending the conversation surrounding GTA experiences.

Having strong support and connections with other GTAs and people in their department was, as mentioned above, one of the main ways GTAs were able to overcome challenges. However, even with the best community and support in the world, people will still face hard days and not know what to do in every situation. The ways participants in this study chose to overcome certain trials were outlined above, but more could be said regarding how to overcome the various challenges GTAs will be faced with as they seek to teach, learn, and grow in their role. Based on the advice participants shared in these interviews, I would like to outline other ways of withstanding the hardship and confusion that may arise for future GTAs.

Taking Time to Rest and Play. In addition to working things out with other instructors, it would be valuable for GTAs to make sure they are scheduling in regular time in their daily lives to rest and have time away from their work. Over half of the GTAs I interviewed mentioned needing to take time to rest or go do things they love to do during the semester in order to stay sane and do their jobs well. Madison mentioned that this time away from work is where she felt she could become refreshed and ready to return to her computer screen to do her grading and teaching duties. While being both a student and a teacher at the same time brings about a multitude of responsibilities and assignments to complete, taking regular breaks to work on things they love outside of academia can help GTAs feel less overwhelmed and more energized. Jeremiah mentioned this exact practice when he was sharing some advice for future GTAs by stating he would 
always "be sure to, to space out some time in the day, do something that I like doing, whether it's play a game, talk to my roommates, watch a movie, anything like that" as a way to rest his mind so he could be on his "A-game" as an instructor. This time to do things that they love is invaluable, and some GTAs need to be encouraged to do this. By engaging in things like playing games with friends, reading a book for fun, or going for a short walk, GTAs are able to separate their lives from the work they do in a healthy way.

Maintaining Healthy Boundaries. In addition to taking time out of their work to rest, reflect, and play, GTAs should also work to maintain boundaries when it comes to being both a student and a teacher. It can be very easy to let teaching responsibilities creep into personal study time, or vice versa. If GTAs do not carve out time for each of their responsibilities, they may end up struggling to get things done. This is not easy to do, as it becomes difficult to know how to separate personal schoolwork from grading, teaching, and planning. It would be wise for GTAs to plan out when they want to complete their GTA tasks and also schedule out other times for them to do their own research and school assignments. When telling me about what she wished future GTAs would know about maintaining boundaries for personal schoolwork and teaching, Bec said "it's important that those two things stay very separate. And I think GTA's in the future need to understand that you can be impactful without being, um, without blurring those boundaries. And I think that's really, really important.” By taking this advice, future graduate students can proactively help themselves not have as much difficulty when it comes to having enough time for everything they need to do. Putting effort into having good time management is one-way GTAs can accomplish this. Additionally, scheduling 
out specific time for these responsibilities can aid the sensemaking process as GTAs work to understand their own interactions with students and their own professors. These ideas for GTAs can help them as they work through challenges and even potentially prevent certain challenges that may arise. Understanding how GTAs communicate about challenges, make sense of them, and then act in ways that help them overcome is valuable because this insight can help update and improve the entire experience of GTAs: from the first day of training all the way until their graduation.

\section{Research Implications}

\section{Implications for Communication Studies}

Not only does this research have implications for research on GTAs, but it also contributes to a larger context within the realm of communication studies in multiple ways. This data illuminates a connection between instructional communication and organizational communication which has not been previously crossed or acknowledged within the field. This study disrupts the idea that sensemaking theory is only helpful for or meant to be used within formal "organizations"; there is evidence of sensemaking happening within the communication within institutions of higher education which are not historically thought of as organizations. There are implications for making more connections that could benefit scholars from both realms as they seek to understand the theoretical and practical approaches to overcoming challenges in school, work and personal life.

To answer my first research question, I asked participants to describe their own communication about challenges as well as talk to me about them. This provided me with 
two opportunities to answer how they communicate about challenges: one from how they self-identified their own communication and another from how I interpreted their communication in our conversations. Both of the pathways to uncovering how GTAs talk about challenging situations yielded four different results. In their responses, GTAs revealed that they talk about challenges openly, they are willing to describe their feelings, and they prefer to communicate about challenges both within themselves and in conversations with others (fellow GTAs, students, and outsiders). By asking GTAs to describe their past communication and comparing it to their immediate communication within the context of their interview responses, we can see more clearly the entire picture of their communicative processes. This study provides us not only with a glimpse into how GTAs communicate about the challenges they face, but also who they prefer to communicate with about such things. This finding can help us know how to create better spaces for communication about challenges for GTAs so that they are able to do so in productive ways.

In response to the next research question, I found that GTAs engage in sensemaking through multiple practices that became clearer through their recollection of various processing strategies. GTAs do go through sensemaking in stages, and it is clear that they make sense of challenges in phases that map directly onto the stages of sensemaking that Weick (1995) outlined in his theory about organizing within workplace contexts. This is particularly significant in that it provides us with specific information about how GTAs choose to interpret the challenges that happen to them. Primarily, they find themselves wanting to communicate about challenges with other people. They want to talk things 
through. However, this does not stop there, and the GTAs in this study explained that their own techniques to help themselves make sense of things includes enactment, selection, and retention. They do not merely discuss challenges; they like to do so in a specific format. This format is not random. It follows key steps of communication and interpretation that have been analyzed and examined by organizational communication scholars for almost thirty years. The way in which we choose to make sense of things has implications for what we can do to help future GTAs have the support they need and the space to communicate about challenges.

Beginning to bridge the gap. As touched on above, this research not only provides GTAs and their program coordinators with insight into how they should craft their programs, but it also has implications for research conducted on sensemaking. One of the most profound aspects of this research is the way in which the findings can help us as communication scholars link two different subfields of our discipline: organizational and instructional communication. Traditionally, these divisions are kept separate due to the nature of their settings and the differences between organizations as arenas for organizing and classrooms as spaces for instruction. However, the findings from this study show us that there may be more in common between these two areas of the field than scholars have previously recognized.

How do pedagogy and workplace communication connect? We see a connection in the sensemaking practices employed by GTAs in this study. Without prompting, GTAs answered questions about how they process through information by talking about their own sensemaking with their supervisors and peers. For over half of the GTAs in this 
study, sensemaking occurred in the same stages as outlined by Weick regarding organizing (enactment, selection, retention). For the other participants, the three stages happened as well, but merely with some movement back and forth between the stages. In this instance, we see sensemaking as a language that can help us speak across communication subfields. By looking at new teachers through the lens of organizational practices, it is clear that the communicative processes that happen in other workplaces are happening in their own way within the higher education institution. While the rules and specific content of communication may be drastically different in these spaces, the characteristics and structure of it may be the same. The way in which teachers communicate to their students follows similar structures to that which is happening in meetings within corporations and nonprofits. These similarities provide scholars with the opportunity to further engage people from across various sides of communication subdisciplines to find commonalities and collaboration about best practices. By learning about how instructors make sense of challenges, organizational communication scholars may find out information about their own interpretations of challenges and how they can move forward with strategies used by teachers. Because we do not know much about sensemaking in instructional communication, this research could act as a catalyst for further study into how this occurs. There are more ways we can learn from both of these subdivisions of communication than scholars may be aware of, and this study shows us how we can take action to improve this for the future.

More specifically, the way in which GTAs in this study chose to make sense of their challenges in tandem with other colleagues to be able to craft approaches to overcoming 
them could be useful for organizations. Instead of waiting to let this happen organically for only some employees who have the preexisting relationships and connections needed to make sense of difficulty in the workplace, supervisors and company leaders could help create spaces for this type of collaboration to happen in team meetings, smaller mentoring sessions, or within other organizational spaces. On the other hand, this type of collaboration and sensemaking could be formally acknowledged in GTA groups. In doing this, research done in the organizational communication world could be brought into the training that is done for GTAs in order to help people understand and participate in sensemaking in ways that actually help them overcome challenges. For example, at the university level, there could be specific training for all GTAs regarding what to do when students plagiarize or are academically dishonest within each department. There could also be informal meetings for GTAs to get together and, as Madison put it in her interview, "just vent" about the challenges they are facing within their role. In these different spaces, communication about challenges via reflexive sensemaking could be encouraged and the connection between instructional and organizational communication could be strengthened.

\section{Limitations \& Future Directions}

For my thesis work, there was an obvious hindrance and limitation to being able to do the most effective research possible: COVID-19. Had it not been for the pandemic, I would have been able to interview participants in person at SJSU and have been able to better pick up on their emphasis, mannerisms, and many other valuable elements of nonverbal communication within their responses. The pandemic also greatly affected my 
time and the scope of my research. I would have had more time to collect my data, analyze it, and go over it all because I would not have had to do as much work when it came to learning the instructions and outlines for conducting research via Zoom. With more time to spend in the field, I could have interviewed more GTAs, held group interviews, and even conducted some sort of small debrief survey to ask participants follow-up questions. Also, because of the ever-changing nature of the pandemic and all of the regulations constantly changing from being locked down to the rollout of the vaccine, it was difficult to know if there were new challenges or changes to what participants may have said to me in the interviews. While I was able to interview thirteen different GTAs, these participants were from many of the same departments, and I believe some of them may have encouraged one another to participate in this after doing so themselves. In the future, I would like to have a more diverse group of participants with every department on campus represented in the data. However, it is worthwhile to note that the pandemic also provided me with an opportunity and a unique position to study challenges during a time when people were being faced with some of the hardest, most challenging months of their lives. I count the COVID-19 pandemic as both a limitation and a huge opportunity that set the stage for valuable and specific data to be collected that would not have been found otherwise.

Additionally, because I was not able to interview more GTAs, I am unable to generalize my specific findings to larger GTA communities. I can only offer what could work based on what was found within this small subgroup of GTAs. In the future, I would like to study more GTAs at other universities and from other departments to be 
able to see how they engage in sensemaking practices within their informal and formal meetings. I would also have liked to have a more diverse sample of GTAs from more departments and from different backgrounds. Because these GTAs represented within this study are from the same university, there may be certain things that other GTAs from institutions outside of SJSU might bring to the table that are not a part of this work. This research is an argument for more GTA research to be conducted in general and doing so at more than one university is the way to adequately update the current literature. Hopefully, future scholars seeking to study GTAs will want to do some more comparative analysis of these programs and the effects that COVID-19 has had on this community.

\section{Final Remarks}

Getting to sit and talk to people via Zoom who had gone through the same hard things that I have was a powerful experience for me. I have consistently felt like I needed to have all the answers, that I cannot let people see me questioning myself, and that I should only share about the good side of my GTA experience so as to not discourage my fellow cohort members. This, I can see now, was doing a disservice to myself and my team because I was not always authentic. There is beauty to be found in talking about the messy, the painful, or the confusing parts of teaching. As each participant shared their story with me, the desire within me to "have it all together" began to quiet, and a newfound sense of courage grew in its place.

After having gone through some challenging situations myself as a GTA such as the ones mentioned above and talking with others who had been through similar as well as 
drastically different challenges, I realized more than ever just how valuable this research really is. There are so many GTAs who struggle on their own and do not have outlets for processing what is happening in their lives. Not only was it helpful to listen to other people affirm some of the things I had experienced, but it became even more real to me with each interview that this role is one that people cannot afford to take on without support. The way the participants illuminated the intersections of their student, teaching and personal lives gave me so much to report back. I wish we all could have sat having coffee together for hours.

As I read over the pages of transcription, I find myself continually in awe of the resilience of these graduate students who are doing their best to complete their coursework while simultaneously navigating the world of online instruction. They shared things with me that will lay the groundwork for those who will come after them to be able to find success in their positions. The fortitude these students have displayed when handling challenges has come to life both in my heart and in the pages of this document, helping me see just how powerful graduate students are.

After going over all of this research thoroughly, I find myself convinced of something: we often reach out to others as a way to ground ourselves in an ever-changing world. We look to those in our various circles and talk with them as a way to make sense of all that is going on around us - of the interactions we engage in daily, the relationships we have forged over the years, and even our own identities. Communication is the medium through which we find connection, and as the GTAs in this study so clearly revealed to me, it is through connection that we find the strength to press on. 
My experience as a GTA at SJSU has been anything but normal, as most people would probably expect. However, I feel as though the norm for me eventually looked like preparing for everything that I had practiced to change at every juncture. I felt certain about nothing except for the constant uncertainty. Almost everything my cohort members tried to prepare me for was ripped out from under me in the span of the past two years, and I had to learn how to grapple with that. Was I going to let that ruin me? Should I quit? Would I let the never-ending changes cause me to be overtaken by fear? Was there something good to be found in the mundane, tedious work that is online education? There were definitely days where I felt like I could give up, but I never did. I learned, with the help of my cohort and the professors guiding me, that we never fully "arrive" as teachers and that we will always be learning, changing, messing up, falling and getting back up again. It is in the midst of this dance where we learn to become great instructors.

The strength needed to continue waking up, doing our jobs, and just being present in class was particularly fleeting for many people during the past year, especially for those who had been hit hard by the plethora of negative effects caused by the COVID-19 pandemic. The same sentiment from the beginning of this study has been weaved throughout its entirety: we need each other. There is no way I would have made it to this point in my academic career without the support of my GTA community, my advisor, and those in my personal life. Many of my participants have the same feelings and mentioned that they "have no idea where I would be" without those individuals who guided them and supported them in moments when they felt like giving up. The past year has been painful, and many of us have grieved for months on end. While nothing could have 
prepared any GTA for what teaching and going to school during a pandemic would be like, the way my participants have chosen to make sense of challenges and rise above some of these uncomfortable situations gives me hope for the future of higher education.

After talking with other GTAs from across a mix of different departments, I have come to realize that we may never fully grasp how the challenges we have been faced with have affected us. It may take years to be able to look back and see exactly how we have grown and how we have learned to overcome things that may not come easy. Like the GTAs I interviewed, I find myself grateful for the experiences I have had in this role, and I would not ever change them because it was through these challenges that I have become the instructor that I am today.

If there is one thing anyone could take away from this research, I hope it to be this: we need support to get through challenging situations. We need to be connected to one another to traverse the terrain of academia, but also the world outside of higher education. The kind words of a friend on a hard day, the encouragement from a mentor when you have no clue what action to take, and the space to just be who you are can help us power through the dark times. For GTAs, it was made apparent in the pages above just how much we need to maintain connection with each other and that we need the space to process through our thoughts, emotions, and experiences as we navigate being both a teacher and a student simultaneously. This means GTAs should be supported beyond their training. As Nyquist and Wulff (1996) argued, "universities have a special obligation to prepare the professoriate of tomorrow, and it is not sufficient for TAs to learn their roles without clear goals and support for their learning." I look forward to 
seeing even more GTAs excel and not merely put their heads down to push through challenges on their own, but rather walk with their heads held high as they stand on the strength they have gained from being supported by their communities. 


\section{References}

Becker, E. A., Easlon, E. J., Potter, S. C., Guzman-Alvarez, A., Spear, J. M., Facciotti, M. T., ... Pagliarulo, C. (2017). The effects of practice-based training on graduate teaching assistants' classroom practices. CBE-Life Sciences Education, 16(4). https://doi.org/10.1187/cbe.16-05-0162

Beltman, S., Mansfield, C., \& Price, A. (2011). Thriving not just surviving: A review of research on teacher resilience. Educational Research Review, 6(3), 185-207. https://doi.org/10.1016/j.edurev.2011.09.001

Blouin, D. D., \& Moss, A. R. (2015). Graduate student teacher training. Teaching Sociology, 43(2), 126-136. https://doi.org/10.1177/0092055x14565516

Bruss, K. (2009). "You've got mail": Addressing effective e-mail communication in new graduate teaching assistant training. Communication Teacher, 23(4), 162-166. https://doi.org/10.1080/17404620903222157

Council of Graduate Schools. CGS Research - 2019 Report. https://cgsnet.org/.

Duckworth, A. (2019). Grit. Vermilion.

Fassett, D. L., \& Warren, J. T. (2012). Coordinating the communication course: A guidebook. Bedford/St. Martins.

Feezel, J. D., \& Myers, S. A. (1997). Assessing graduate assistant teacher communication concerns. Communication Quarterly, 45, 110-124.

https://doi.org/10.1080/01463379709370055

Friedman, J. (2017). 10 Universities where TAs teach the most classes. U.S. News and World Reports. https://www.usnews.com/education/best-colleges/the-short-listcollege/articles/2017-02-21/10-universities-where-tas-teach-the-most-classes

Golish, T. D. (1999). Students' use of compliance gaining strategies with graduate teaching assistants: Examining the other end of the power spectrum. Communication Quarterly, 47(1), 12-32. https://doi.org/10.1080/01463379909370121

$\mathrm{Gu}, \mathrm{Q}$. (2014). The role of relational resilience in teachers' career-long commitment and effectiveness. Teachers and Teaching, 20(5), 502-529. https://doi.org/10.1080/13540602.2014.937961 
Houston, J. B., \& Buzzanell, P. M. (2018). Communication and resilience: Concluding thoughts and key issues for future research. Journal of Applied Communication Research, 46(1), 26-27. https://doi.org/10.1080/00909882.2018.1426691

Lucas, K. (2011). Blue-collar discourses of workplace dignity: Using outgroup comparisons to construct positive identities. Management Communication Quarterly, 25(2), 353-374. https://doi.org/10.1177/0893318910386445

Mazzola, J. J., Walker, E. J., Shockley, K. M., \& Spector, P. E. (2011). Examining stress in graduate assistants: Combining qualitative and quantitative survey methods. Journal of Mixed Methods Research, 5(3), 198-211. https://doi.org/10.1177/1558689811402086

Myers, S. A. (1995). The induction of graduate teaching assistants: A communication model of the socialization process. Kent State University.

National Center for Education Statistics. (2020). Postbaccalaureate Enrollment. https://nces.ed.gov/programs/coe/indicator chb.asp.

Nicotera, A. M. (2020). Origins and traditions of organizational communication: A comprehensive introduction to the field. Routledge.

Nyquist, J. D. (1991). Preparing the professoriate of tomorrow to teach: Selected readings in TA training. Kendall/Hunt Pub. Co.

Nyquist, J. D., \& Wulff, D. H. (1996). Working effectively with graduate assistants. Sage.

Owen, W. F. (1984). Interpretive themes in relational communication. Quarterly Journal of Speech, 70(3), 274-287. https://doi.org/10.1080/00335638409383697

Owen, W. F. (1985). Thematic metaphors in relational communication: A conceptual framework. The Western Journal of Speech Communication, 49, 1-13. https://doi.org/10.1080/10570318509374177

Payne, H. J., Cummings, R. D., \& Greunke, E. J. (2015). Graduate assistant dissent expression: Navigating the role of student and employee. The Northwest Journal of Communication, 43(1), 103-132.

Pytlak, M. A., \& Houser, M. L. (2014). Because I'm the teacher and I said so: GTA use of behavior alteration techniques to establish power and credibility in the college classroom. Western Journal of Communication, 78(3), 287-309. https://doi.org/10.1080/10570314.2014.893010 
Rhodes, T. D. (1997). Graduate teaching assistant training: Examining issues of socialization and emotionally painful incidents in the classroom. North Dakota Journal of Speech \& Theatre, 10(1), 52-63.

Reinard, J. C. (2008). Introduction to communication research. McGraw-Hill Higher Education.

Saldaña, J. (2021). The coding manual for qualitative researchers. Sage.

Schwartzman, R. (2020). Performing pandemic pedagogy. Communication Education, 69(4), 502-517. https://doi.org/10.1080/03634523.2020.1804602

Smollin, L. M., \& Arluke, A. (2013). Rites of pedagogical passage: How graduate student instructors negotiate the challenges of first-time teaching. Teaching Sociology, 42(1), 28-39. https://doi.org/10.1177/0092055x13502181

Spialek, M. L., \& Houston, J. B. (2018). The influence of citizen disaster communication on perceptions of neighborhood belonging and community resilience. Journal of Applied Communication Research, 47(1), 1-23. https://doi.org/10.1080/00909882.2018.1544718

Staton-Spicer, A. Q., \& Marty-White, C. R. (1981). A framework for instructional communication theory: The relationship between teacher communication concerns and classroom behavior. Communication Education, 30(4), 354-366. https://doi.org/10.1080/03634528109378491

Stephens, K. K., Jahn, J. L., Fox, S., Charoensap-Kelly, P., Mitra, R., Sutton, J., ... Meisenbach, R. J. (2020). Collective sensemaking around COVID-19: Experiences, concerns, and agendas for our rapidly changing organizational lives. Management Communication Quarterly, 34(3), 426-457. https://doi.org/10.1177/0893318920934890

Suspitsyna, T. (2013). Socialization as sensemaking: A semiotic analysis of international graduate students' narratives in the USA. Studies in Higher Education, 38(9), 1351-1364. https://doi.org/10.1080/03075079.2011.629343

Teasdale, R., Ryker, K., \& Bitting, K. (2019). Training graduate teaching assistants in the geosciences: Our practices vs. perceived needs. Journal of Geoscience Education, 67(1), 64-82. https://doi.org/10.1080/10899995.2018.1542476

Tracy, S. K. (2013). Qualitative research methods: Collecting evidence, crafting analysis, communicating impact. Wiley-Blackwell. 
U.S. Department of Labor, Bureau of Labor Statistics. (2018). Graduate teaching assistants. https://www.bls.gov/oes/current/oes251191.htm

Weick, K. E. (1995). Sensemaking in organizations. Sage.

Yan, D., Sengupta, J., \& Hong, J. (2016). Why does psychological distance influence construal level? The role of processing mode. Journal of Consumer Research, 43(4), 598-613. https://doi.org/10.1093/jcr/ucw045

Young, S. L., \& Bippus, A. M. (2008). Assessment of graduate teaching assistant (GTA) training: A case study of a training program and its impact on GTAs.

Communication Teacher, 22(4), 116-129.

https://doi.org/10.1080/17404620802382680 


\section{Appendix A}

\section{INTERVIEW SCRIPT}

RQ1: How do GTAs communicate about the challenges that they experience?

RQ2: How do GTAs at SJSU make sense of these challenges?

RQ3: What actions do GTAs take to overcome these challenges?

\section{INTRODUCTION}

A. [Establish Rapport] Thanks for meeting with me today! I thought it would be a good idea for us to connect since I am doing a study on how GTAs experience and overcome challenges. I am looking forward to hearing about your time as a GTA.

B. [Purpose/Confidentiality of students] In our time today, I would like to ask you some questions about certain situations you've encountered in order to learn more about you. Hopefully, some of the things we talk about today can help future GTAs going through similar experiences. Before we get started, I must instruct you to not name any specific students or provide me with any information that could result in the identification of a specific student. This includes not providing the department, major, or any demographic characteristics of students in your responses. Does this make sense? Do you commit to abiding by this?

C. [Motivation] Thank you. From our interaction, I hope to gain an understanding about how you communicate about specific challenges you have dealt with and how you have overcome them (or are overcoming them).

D. [Timeline] Our time together should take approximately thirty minutes to one hour, but please feel free to expand upon your responses as much as you'd like.

(Transition: Let's begin by talking about your experiences as a GTA...)

\section{BODY}

\section{A. So, tell me about what brought you to the GTA position...}

1. What made you apply for the position? What about being a GTA were you drawn to?

2. What do you love about teaching? What has drawn you to teaching or assisting other teachers?

3. What was/is your overall experience like?

a. Can you tell me about the first time you interacted with your cohort as a GTA?

i. What was it like?

b. What various responsibilities are/were you in charge of? 
c. Could you describe your favorite experience as part of this group?

d. What was/is your favorite part of being a GTA in your program?

(Transition: So, we have talked a bit about how you became GTA and what you love about it! I'd like to hear more specifically about some of the more trying parts of your experience...)

B. What are some of the challenges you have faced as a GTA?

1. What would you say is the hardest part of being a GTA? GTA?

a. Can you think of any other challenges you have faced during your time as a

b. What did you find particularly challenging about those situations?

c. What did you do in those situations?

d. How did you communicate about what was happening? How do you talk about these challenges with others?

1. What were you thinking or feeling when these things were occurring?

a. Who did you talk to/communicate with when this was happening?

b. What did you say/communicate?

2. How did you choose to make sense of or process through that challenge?

3. What did you wish you would have had during those situations?

a. What would you do differently?

b. What would you tell other people who are going through the same or a similar experience?

(Transition: So, let's examine how you handled these challenges and grew from those experiences...)

C. Can you tell me about how you were able to overcome those challenges?

1. How did you rise above the conflict/situation? What actions did you take?

a. Can you give an example of this?

b. What did you do exactly?

c. Some GTAs have reported experiencing:

- Feelings of inadequacy

- Stress about their own responsibilities as a student

- Not having student participation in their online classes

- Not knowing how to handle student misconduct/plagiarism/other issues

- Not feeling prepared for their job

- Personal struggles

...during their time teaching...has any of this ever happened to you? What did you do? If not, how would you handle these things? What would you do in that situation? 
2. How do you know the situation had been solved or that you had "overcome"?

3. What helped you when things were difficult?

a. What resources did you use to navigate these challenges?

4. What did you learn from having to tackle those obstacles/challenges?

a. How has this impacted your teaching?

b. How has it impacted who you are?

\section{CONCLUSION}

A. From what I have already asked you, is there anything else you'd like to tell me about your time as a GTA or any of the problems you have experienced?

B. It has been a pleasure talking with you. Thank you for taking the time to meet with me today. 


\section{Appendix B}

\section{INTERVIEW INTRODUCTION PROTOCOL}

Thank you for your willingness to participate in this study! As you've already read, I am a graduate student in the Communication Studies department at San José State University, and I am currently pursuing my master's thesis. I am very interested in the role of Graduate Teaching Associates and their experiences both in and outside of the classroom. More specifically, I am curious about the difficult situations GTAs face and how they make sense of and respond to those circumstances.

The interview we are about to embark on will take approximately 30-60 minutes, but you are free to share as much as you'd like. This will include questions pertaining to your personal experiences regarding difficulties and challenges you have faced as a GTA. Please do not hesitate to stop me at any point in the interview if you need clarification or if any of the questions are confusing.

I will be video recording (or audio recording) this interview so I may accurately document the information you share with me. However, if at any time during the interview you wish to discontinue the use of the video or audio, please feel free to let me know. The interview data will remain confidential, and your name will not appear in my final report. You will be assigned a pseudonym and will not be able to be identified in any of the research.

By signing the consent form, you have agreed to participate in this study and to allow me to have access to your responses throughout the data collection process. Please understand that you are under no compulsion to take part in the study. Feel free to take as much time as you need to reread through the consent form, and if you have any questions, please let me know so that I can clarify any portions that you may find confusing.

Do you have any questions or concerns before we begin? Then with your permission we will begin the interview. 


\section{Appendix C}

\section{DEMOGRAPHIC QUESTIONNAIRE}

Directions: Thank you for taking the time to fill out this form. You are not required to answer the following questions. This information will remain strictly confidential. Your name and demographic information will be kept separate from your responses. Only the researcher will have access to your individual data and any reports generated as a result of this study will use pseudonyms when connected to an interview answer. Please fill out this form and send it back to the researcher upon completion. Thank you!

Demographic Information

Name:

1. What is your age? (Please highlight one of the following)

a. Younger than 20 years old. e. 35-40 years old

b. 20-25 years old f. $40-45$ years old

$\begin{array}{ll}\text { c. } 26-30 \text { years old } & \text { g. } 50+\text { years old }\end{array}$

d. 30-35 years old

2. What is your gender? (Please fill in your answer)

3. What is your ethnicity? (Please fill in your answer)

4. What department do you work in as a GTA? (Please fill in your answer)

5. How long were you or have you been a GTA? (Please fill in your answer)

6. When were you employed as a GTA at San Jose State University? (Please fill in your answer) 


\section{Appendix D}

\section{CONSENT FORM FOR PARTICIPATION IN RESEARCH}

\section{TITLE OF STUDY}

How do you handle that? How graduate teaching associates engage in sensemaking practices to overcome challenges

\section{NAME OF RESEARCHER}

Laura Bell, Department of Communication, San Jose State University

Faculty Supervisor: Dr. Tabitha Hart, Department of Communication, San Jose State University

\section{PURPOSE}

The general purpose of this research is to explore the difficult situations GTAs encounter and how they make sense of and overcome them. The results of this study will be used to help and guide future GTAs who go through similar experiences.

\section{DESCRIPTION OF PROCEDURES}

You will be asked to participate in the interview process via Zoom, and the approximate total time of your involvement with the interview will be 30-60 minutes. The said interview will only be audio and video recorded with your consent and will be transcribed by the primary investigator, Laura Bell.

\section{RISKS}

Participants could potentially spend more time reflecting on stressful or difficult situations they have encountered as a GTA. This could bring about different negative emotions or feelings. Participants may find themselves feeling stressed out about the challenging situations they have faced in their time teaching. However, the participants will not be solely asked about those things. They will also be asked about how they overcame those situations and grew from them. The majority of the interviews consist of questions that are about their experiences as GTAs. Participants will only be asked about these potentially stressful situations briefly, and the point is not to get them to discuss matters that would reflect badly on superiors or their students. Given that some departments may have very few GTAs, reporting the name of a department could lead to re-identification of participants based on contextual information provided (i.e., employers/supervisors and colleagues may likely be able to identify participants if they read the final thesis). Even if the department is not named, there is still a possibility that someone might be able to recognize participants from contextual information provided in the interview.

Please indicate below if you would prefer to NOT have your department name reported and have your discipline-specific information removed before publication (check one):

Yes, I would like all discipline-specific information removed. 
No, I consent to having my discipline-specific information reported.

\section{BENEFITS}

While there are no direct benefits to the individual participants besides getting an opportunity to share their experiences, the information that is collected in this study may help future educators, GTAs, and anyone studying the social sciences. The potential indirect benefits of this study are that participants will have the opportunity to describe, make sense of, and process their experiences of handling challenges and rising above them during their time as a GTA.

\section{PARTICIPANT RIGHTS}

Your participation in this study is completely voluntary and you may refuse to participate. If you agree to participate, you have the right to stop at any time with no penalty. You also have the right to skip any interview question that you do not wish to answer. If after your participation you experience any undue anxiety or stress, you are encouraged to contact San Jose State University's Counseling and Psychological Services department (CAPS) for consultation. Their contact information is here for your reference: phone: 408-924-5910; email: counseling.services@ @ sjsu.edu

\section{CONFIDENTIALITY}

In order to protect your confidentiality, you will be given a pseudonym which will be maintained to keep your answers separate from who you are. Your responses will be kept confidential throughout the entirety of the duration of this study. The primary researcher and their faculty supervisor will be the only people to have access to individual data. Any reports generated as a result of this study will use the assigned pseudonyms when connected to an interview exemplar. The researcher is required to keep a copy of this informed consent document, but it will be kept separate from the study results. As mentioned above, there are limits to confidentiality in this study, so please be sure to indicate if you wish for contextual information to be removed prior to the publication of the final thesis.

\section{QUESTIONS OR PROBLEMS}

You are encouraged to ask questions at any time during this study.

- For further information about the study, please contact Laura Bell at (408) 891-2824 or laura.bell@sjsu.

- Complaints about the research may be presented to Anne Marie Todd, Ph.D., Department of Communication Studies: Annemarie.todd@ @jsu.edu

- For questions about your rights or to report research-related injuries, please contact Pamela Stacks, Ph.D., Associate Vice President of The Office of Research: (408) 9242479.

\section{PARTICIPANT SIGNATURE}


Your signature indicates that you voluntarily agree to participate in the study, that the details of the study have been explained to you, that you have been given ample time to read this document, and that your questions have been satisfactorily answered. You may request a copy of this consent form for your records.

Participant's Name (printed)

Participant's Signature

Date

\section{INVESTIGATOR STATEMENT}

I certify that the participant has been given adequate time to read and learn about the study and all of his/her questions have been answered. It is my opinion that the participant understands the purpose, risks, benefits, and the procedures that will be followed in this study and has voluntarily agreed to participate. 